\title{
DOES PRODUCTION LABELING STIGMATIZE CONVENTIONAL MILK?
}

\author{
A Thesis \\ Presented to the Faculty of the Graduate School \\ of Cornell University \\ in Partial Fulfillment of the Requirements for the Degree of \\ Master of Science
}

by

Christopher Axtell Kanter

February 2010 
(C) 2010 Christopher Axtell Kanter 


\begin{abstract}
Production labeling is a common approach for differentiating otherwise similar products in the marketplace. While these labels may convey positive messages to consumers about the new product, they may simultaneously stigmatize the conventionally-produced product by highlighting perceived problems. The net economic result for producers can be negative since consumers may decrease their willingness to pay for the conventional product that dominates the market, while the new product has a relatively small market share. This research identifies this stigma effect in the case of milk, where the introduction of rBST-Free and organic milk reduces consumers' willingness to purchase conventional milk.

In this thesis, the question of whether production labeling is driving consumer's bias against conventional milk is investigated in an experimental setting by eliciting the willingness to pay in a sample of Cornell University staff and graduate students for milk produced via different production methods and of varying fat contents. Through altering the order in which participants bid for the different types of milk and analyzing the resulting data using a two-limit random-effect Tobit model with instrumental variables, we find that consumers are indeed willing to pay a premium for rBST-Free and organic milk despite a lack of scientific evidence regarding harmful effects of rBST on human health.

The results illustrate that, by varying the order in which experiment participants were allowed to taste and learn information about milk produced using different techniques, we are able to demonstrate that participants were willing to pay less for milk produced using rBST after being exposed to rBST-Free and organic milk, and likewise, willing to pay more for rBST-Free and organic milk after being exposed to milk produced using rBST. In a situation where milk produced using all three
\end{abstract}


techniques is available, the end result is a higher price charged for rBST-Free and organic milk and decreased revenue for farmers and distributors who deal in milk produced using hormones. The implications of the experiment are fairly straightforward - production labeling can indeed be a strong influence on consumer's perception of a good, and producers of conventional goods in markets where alternative products are being introduced need to be aware of the potential impact of the availability of the new product on the demand for the conventional product. 


\section{BIOGRAPHICAL SKETCH}

The author was born February 12, 1981 in Plattsburgh, New York. His early years were spent in White Plains, New York. In 1994, he moved to Ithaca, New York, where he graduated from Ithaca High School in 1999, and subsequently graduated with a degree in economics from Cornell University in 2003.

After a hiatus from academics, he found himself back at Cornell University once again in 2005, this time studying dairy economics under Professor Harry M. Kaiser. The author is currently a $\mathrm{PhD}$ candidate at the University of Wisconsin, Madison where he is focusing on agricultural production in the Agricultural and Applied Economics department. 


\section{ACKNOWLEDGEMENTS}

I am extremely grateful to Harry Kaiser. His experience and guidance has been an invaluable resource. Without his support I could not have conducted any experiments, completed this thesis, or continued my education in Wisconsin. Thank you so much Harry.

I would also like to thank Kent Messer. Kent's knowledge of experimental economics was fundamental to conducting our experiments, and his input and editing was vital to improving the quality of this paper.

Many thanks to William Schulze, whose advice in designing the experiment was especially helpful in determining the direction of our research.

Special thanks to Anita Vogel. Anita was a life saver on multiple occasions when we ran into problems running the experiments, as well as providing most excellent company during the long process of writing this paper.

This work was possible due to the support of the New York State Milk Promotion Board, the National Institute for Commodity Promotion Research and Evaluation, and the National Science Foundation. 
Biographical Sketch...........................................................................................ii

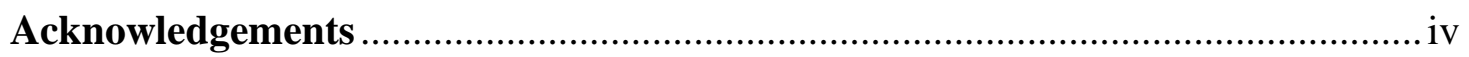

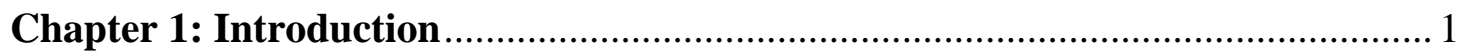

Chapter 2: Literature Review ............................................................................... 4

2.1 Stigma and its Influence on Consumer's Perception

of rBST-Free Milk ........................................................................................... 6

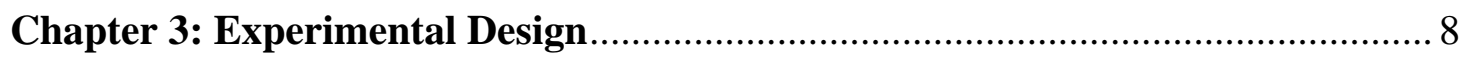

3.1 Experiment Parts A and B: Understanding the Incentive

Compatibility of the BDM Mechanism .............................................................. 9

3.2 Experiment Part C: WTP for Milk ……………………………………... 12

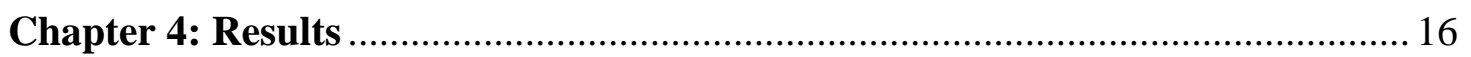

4.1 Difference in WTP Between rBST-Free and

Conventional Milk.......................................................................................... 22

4.2 Difference in WTP Between Organic and Conventional Milk .................... 25

4.3 Difference in WTP Between Organic and rBST-Free Milk ......................... 26

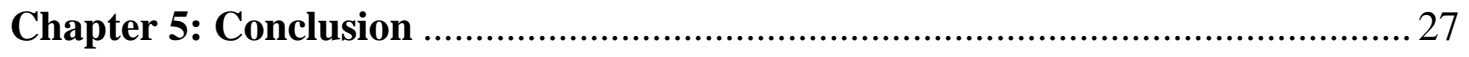

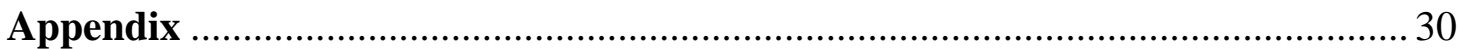

Appendix 1: Experiment Instructions............................................................... 30

Appendix 2: Tasting Template ………………………………....................... 37

Appendix 3: Nutrition Information ................................................................ 38

Appendix 4: Post-Experiment Questionnaire ...................................................... 39

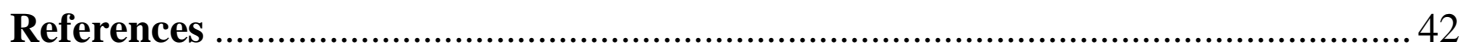




\section{LIST OF FIGURES}

Figure 1: Percentage of subjects willing to pay at a particular price

by the order the milks were presented......................................18 


\section{LIST OF TABLES}

Table 1: Experiment design ..........................................................................

Table 2: WTP and tasting values for milk by fat type and production method ............ 16

Table 3: Average WTP for milk by fat type, production method, and order of tasting ............................................................................... 17

Table 4: Average tasting values for milk by fat type, production method,

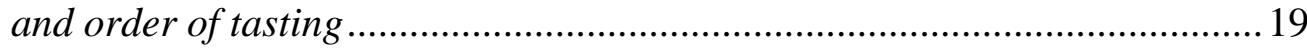

Table 5: Two-limit, random-effect tobit model of differences between WTP ............... 23 


\section{Chapter 1}

\section{Introduction}

Ideally, the labeling of products based on the production methods used should improve consumers' welfare by offering more choices, while at the same time allow producers to differentiate their products and potentially secure additional profits from consumers who are willing to pay (WTP) more for a commodity produced with "preferable" methods. However, labeling to promote the benefits of one technique may also cast the conventional commodity in a negative light. For example, some dairy industry officials are troubled by the labeling of some milk as free of recombinant bovine somatotropin (rBST), which is a synthetically produced version of the naturally occurring hormone bovine somatotropin (bST). Dairy farmers use rBST to boost the milk yields of their dairy cows. Some industry officials believe that labeling some milk products as "hormone free" will stigmatize conventionally produced milk resulting in a reduction in conventional milk or perhaps total fluid milk consumption. ${ }^{1}$ In fact, several states have considered or are considering bans on milk labels that include phrases such as "hormone free" or "contains no artificial hormones" because of the potential stigma effect (Martin 2007).

In ex ante studies of the impact of rBST on consumers' milk purchasing behavior, several factors were found that reduced the demand for milk produced by cows treated with rBST, including the amount of information about rBST that consumers possessed, the quantity of milk they consumed, and how much they were concerned with the level of milk prices (Kaiser, Scherer, and Barbano 1992). This

\footnotetext{
${ }^{1}$ In this article, conventional milk refers to the majority of milk sold in the marketplace, which is unlabeled and may or may not have been produced with rBST. All organic milk and rbST-Free milk comes from farmers that pledge not to administer rbST to their cows
} 
study confirms that, despite assurances from the Food and Drug Administration with respect to the safety of rBST for human consumption, consumers are not convinced that the use of rBST in the general fluid milk supply is in their best interests.

The question of the desirability of rBST for consumers has become even more relevant as large fluid milk processors and retailers, including Wal-Mart, Kroger, Dean Foods, and Starbucks have begun requiring suppliers to cease the use of rBST on their dairy herds. Whether this decision was made with the interests of consumers in mind, or for some other reason, remains unclear. What is clear, however, is consumers are moving away from purchasing conventionally produced milk and towards alternative products that are viewed as safer and more attractive, mainly organic milk and rBST-free milk.

A shift in consumers' preferences away from conventional milk, which may or may not contain rBST, towards rBST-free alternatives is likely to have a significant impact on fluid milk producers. Estimates of rBST adoption rates in the United States vary significantly-from 15\% in Wisconsin herds to as high as 44\% in New York and Texas herds (Barham et al. 2004). According to Monsanto, the largest producer of rBST, $17 \%$ of dairy farmers nationwide used rBST to some degree on their herds and their herds accounted for 33\% of the total number of dairy cows in the U.S. If fluid milk retailers and processors continue to push farmers to stop using rBST on their herds, there will likely be significant costs to the farmers as they transition back to dairy production techniques that do not utilize rBST (Forbes 2008).

In this research, the potential bias of consumers towards conventional milk is examined in the context of stigma, a psychological phenomenon in which an object becomes viewed in a negative manner even when no actual problem or health risk has been identified. The problem is addressed using experimental economics and eliciting WTP for fluid milk produced via differing production methods and varying fat 
contents from adult subjects. Through altering the order in which participants bid for the different types of milk, we find that consumers are willing to pay a premium for organic and/or rBST-free milk despite a lack of scientific evidence regarding harmful effects of conventional milk on human health, and hence it is likely that the trend towards rBST-free milk products is being driven by consumer preferences. 


\section{Chapter 2}

\section{Literature Review}

Early research involving rBST was mainly concerned with how milk production would increase due to rBST adoption and the resulting implications for dairy policy (see, for example, Fallert et al. (1987); McGuckin and Ghosh (1989); and Tauer and Kaiser (1991)). While the supply-side effects of the introduction of rBST into dairy herds were well documented, the effects of introducing an unfamiliar biotechnology into a familiar good, were less well known. A limited number of studies were done to gauge how consumers would react to the presence of rBST in their milk. In a survey of consumers in New York and Virginia, 33\% and $20 \%$ of consumers, respectively, were concerned about the safety of rBST in their milk, and only $30 \%$ and $35 \%$, respectively, believed that milk supplemented with rBST was safe to drink (McGuirk and Kaiser 1991). Additionally, 85\% of the respondents in both states believed that milk containing rBST should be labeled as such, the implication being that they were not fully convinced of the safety of rBST and would like the option of avoiding milk containing it if they so chose. Another study of consumer opinions regarding rBST found that, even taking into account reduced prices from rBST-induced milk production expansion, there would likely be a $1.6 \%$ decrease in milk consumption after the introduction of rBST (Kaiser, Scherer, and Barbano 1992).

The introduction of organic milk is the closest parallel to that of rBST-free milk. While there has been much economic research on organic milk, little has been done on its potential stigma effect on conventional milk. However, there has been some research regarding premiums that consumers are willing to pay for organic milk. Using scanner data and a hedonic econometric model, Bernard and Mathios (2005) 
found that consumers were willing to pay premiums for both organic ( $\$ 0.73$ per gallon) and rBST-free ( $\$ 0.26$ per gallon) milk. The higher price premium for organic milk implies that consumers are willing to pay more for the additional attributes that correspond with organic production. Bernard and Bernard (in press) used experimental price auctions to decompose consumers' WTP for various attributes of organic milk, with an emphasis on the rBST-free and the no antibiotic characteristics. They found that consumers place a significant value on both the rBST-free and the no antibiotics attributes of organic milk. Dhar and Foltz (2005) used supermarket scanner data and a quadratic almost ideal demand systems model to examine the value consumers place on having organic and rBST-free milk in the market place in addition to conventional milk. The authors found substantial benefits to consumers ( $\$ 2.53$ billion) in terms of "competitive" and "variety" effects of having these two products in the market. Based on previous research, therefore, it appears that consumers: (1) prefer having a market that offers choice among conventional, organic, and rBST-free milk, and (2) are willing to pay significant premiums for organic milk, and somewhat smaller premiums for rBST-free milk compared with conventional milk. Consumers' reluctance to embrace rBST as a beneficial technology, as well as the presence of conflicting information regarding the safety of rBST in milk, also bears many similarities to consumers' reactions to the use of genetically modified organisms (GMOs) and other biotechnology in food production (e.g., Noussair, Robin, and Ruffieux 2004; and Lusk, Feldkamp, and Schroder 2004). 


\subsection{Stigma and its Influence on Consumer's Perception of rBST-Free Milk}

It seems that consumers' biases against GMO and rBST share many attributes. The question is why the bias against rBST persists. There is a plethora of information available regarding the safety of rBST and much of it is conflicting. A study of decision-making based on divergent risk information found that decision makers will put more weight on high-risk information than on low-risk information (Viscusi 1997). Another study by Fox, Hayes, and Shogren (2002) on consumers’ reactions to food irradiation came to a similar conclusion-- consumers' WTP for irradiated pork decreased more after exposure to negative information than it increased from exposure to positive information regarding the pork. Additionally, it seems that consumers are not adept at assessing food risks. In an experimental study of consumers' WTP for increased food safety, participants were likely to rely more on personal experience than scientific information when determining their values for avoiding illness (Hayes et al. 1995). This could very well be occurring in the case of rBST. With the ease of acquiring information from the internet, it can be difficult for potential milk consumers to separate reliable information about rBST and human health risks from less reliable sources, especially since Canada, Japan, and a number of countries in Europe currently ban the use of rBST entirely. In a situation such as this, where there is conflicting risk information, consumers may put more weight on the high-risk information (or existing personal beliefs) than on the more reliable low-risk information and adjust their purchasing behavior accordingly.

A topic related to the emphasis on high-risk information is the concept of stigma. Stigma can be thought of as "a negative feature that typically pervades and dominates an otherwise acceptable entity” (Rozin 2004). Stigma is passed on via 
direct contact with a contaminated object in a phenomenon known as contagion (Rozin, Millman, and Nemeroff 1986). Another key element of stigma, at least in Western societies, is that people tend to describe their feelings of revulsion for a stigmatized object in terms of how it impacts their health (as opposed to an object possessing some innate evil characteristic). The effects of stigma have been observed in a variety of economic situations such as the large decrease in home values near some toxic waste sites where the actual health risk posed by these sites in many cases has been relatively small and therefore objective risk alone cannot explain the consumer response (Messer et al. 2006; Dale et al. 1999; Adams and Cantor 2001; Guntermann 1995). Other examples of stigmatized products include cyanide in Tylenol bottles, exploding gas tanks that plagued the Ford Pinto, Firestone tire failures on the Ford Explorer, and mad cow disease with beef.

Regarding the possible stigmatization of conventional milk by organic and rBST-free milk, the properties of contagion and medicalization of risk are especially salient. Milk is considered a healthy, desirable food to consume until the milk undergoes contact with rBST via contagion, despite the lack of substantial chemical change in the milk. People who see the addition of rBST to cows producing milk as a negative action tend to cite possible negative health consequences to humans and cows as justification for their views. Both of these properties play into the possible role of production labeling in stigmatizing conventionally produced milk. By distinguishing between conventionally produced and rBST-free milk through the use of labeling, milk retailers can potentially tap into consumers' fears regarding the safety of conventionally produced milk in order to charge higher prices for rBST-free milk. 


\section{Chapter 3}

\section{Experimental Design}

In order to determine whether the presence of rBST stigmatizes milk to consumers, a three-part experiment was designed (see Table 1). Part A consisted of rounds designed to familiarize participants with the Becker-DeGroot-Marschak (BDM) (1964) bidding mechanism, where induced "cash values” were used. Advantages of the BDM mechanism for private goods include its incentive compatibility in an expected utility framework and demand revealing properties, making it ideal for this experiment. $^{2}$ Part B also used the BDM mechanism and had subjects submit bids to purchase a pencil. Finally, Part C used the BDM mechanism to elicit WTP values for milk produced using three production techniques (conventional, rBST-free, and organic) and three fat contents ( $0 \%$ skim, $1 \%$ lowfat, and 3.25\% whole). Experiment subjects were recruited via e-mail announcements to graduate student and staff e-mail list servers, as well as through PawprintFlash, an online publication containing articles, information, and announcements for Cornell University employees. Fifteen experiment sessions were conducted. Each session lasted approximately one hour and the average earnings were $\$ 15$.

For each part of the experiment, participants received written instructions ${ }^{3}$ with an oral explanation and were provided a chance to ask questions. Subjects were seated

\footnotetext{
${ }^{2}$ As pointed out by Karni and Safra (1987) and Horowitz (2006), the BDM in a private good context where the price is unknown may not be incentive compatible in cases outside of the expected utility model. Their argument is also true with the alternative WTP elicitation mechanisms commonly used in experimental settings, such as the Vickrey auction and nth-price auctions. The foundation of this research is based on the assumption of expected utility and the numerous experimental studies that have demonstrated the demand revealing characteristics of the BDM in induced value settings (i.e., Irwin et al. 1998; Messer et al. 2008).

${ }^{3}$ See Appendix 1 to view the experiment instructions.
} 
Table 1: Experiment design

\begin{tabular}{|c|c|c|c|c|c|c|}
\hline Part & Item for Sale & $\begin{array}{c}\text { Initial } \\
\text { Balance }\end{array}$ & $\begin{array}{c}\text { Range } \\
\text { of } \\
\text { Costs }\end{array}$ & $\begin{array}{c}\text { Bids per } \\
\text { Round }\end{array}$ & $\begin{array}{c}\text { Cash Payoff } \\
\text { Rounds }\end{array}$ & $\begin{array}{c}\text { Exchange } \\
\text { Rate }\end{array}$ \\
\hline A & $\begin{array}{c}\text { Cash Values: } \\
\$ 1, \$ 2.50, \$ 4\end{array}$ & $\$ 5.00$ & $\begin{array}{c}\$ 0.00- \\
\$ 4.99\end{array}$ & 1 & 5 & $2: 1$ \\
\hline B & Pencil & $\$ 0.50$ & $\begin{array}{c}\$ 0.00- \\
\$ 0.49\end{array}$ & 1 & 1 & $1: 1$ \\
\hline C & $\begin{array}{c}\text { Quart of Milk } \\
\text { Fat Types: } 1 \%, 3.25 \% \\
\text { Production Type: } \\
\text { Conventional, } r \text { BST- } \\
\text { free, Organic }\end{array}$ & $\$ 5.00$ & $\begin{array}{c}\$ 0.00- \\
\$ 4.99\end{array}$ & 9 & 1 & $1: 1$ \\
\hline
\end{tabular}

randomly at computers that were equipped with privacy shields, and no communication was permitted between subjects. Experiment data was collected using Excel spreadsheets programmed in Visual Basic. At the completion of the experiment, participants were asked to fill out a questionnaire regarding their milk purchasing behavior and knowledge, their attitudes towards risk, and general demographic information. ${ }^{4}$

\subsection{Experiment Parts A and B: Understanding the Incentive Compatibility of the BDM Mechanism}

Part A consisted of five rounds. At the start of each round, $t$, participants were provided with a $\$ 5$ initial balance, $Y_{t}$, and were presented with a "cash value", $V_{t}$, of

\footnotetext{
${ }^{4}$ See Appendix 2 to view the post-experiment questionnaire
} 
$\$ 1$, $\$ 2.50$, or $\$ 4$ (see Table 1). Participants were then asked to record the highest amount that they would be willing to pay to receive that cash value-we refer to this amount as their "bid," $B_{i t}$. Once all participants recorded their bids, a price, $C_{t}$, was drawn from a random-number table containing values from \$0 to \$4.99 and announced to all the subjects.

As described by Irwin et al. (1998), utility-maximizing subjects in this mechanism submit a bid given an initial income $Y^{0}$ that maximizes:

(1) $\quad E U=\int_{0}^{B} p(C) U\left(Y^{0}+E+V-C\right) d R+\int_{B}^{E} p(C) U\left(Y^{0}+E\right) d R$

Examination of the left side of equation (1) shows that it is not in the best interest of a participant to bid less than her actual WTP. In the event that the randomly drawn price falls between her actual WTP and her stated WTP, the participant loses the opportunity to earn a larger profit. The logic behind not overstating WTP is shown in the right side of equation (1). Participants would not want to submit bids that are greater than their actual WTP_-if a participant bids higher than her actual WTP and the randomly selected price is between her actual WTP and her stated WTP, she could potentially end up paying more than her value for an object. The derivative of equation (1) with respect to $B$ leads to:

(2) $\frac{d E U}{d B}=p(B)\left[U\left(Y^{0}+E+V-B\right)-U\left(Y^{0}+E\right)\right]=0$

Since the probability of the bid being equal to the price is $(p(B)>0$, participants who are maximizing their utilities will submit bids equal to value $(B=V)$, demonstrating the incentive compatibility of the mechanism.

Each round produced two possible outcomes for the participants that depended on their bids and the random price. If the participant's bid was greater than or equal to the random price $\left(B_{i t} \geq P_{t}\right)$, the participant purchased the cash value at the randomly 
selected price, yielding a payoff of $Y_{t}+\pi_{t}-P_{t}$. However, if the participant's bid was less than the price $\left(B_{i t}<P_{t}\right)$, then the participant retained only the initial balance, $Y_{t}$.

The primary objective of Part A was to give subjects an opportunity to learn how the BDM mechanism operates. To this end, the procedures followed those of Noussair, Robin, and Ruffieux (2004); participants were informed that the best strategy for each round was to place a bid equal to the cash value $\left(B_{t}=\pi_{t}\right)$ since that would result in the participants receiving the greatest possible payoff for each round regardless of the price. To reinforce this message, at the conclusion of each round of Part A, participants were given the chance to view the bids from all of the subjects in the round, the random price, and the payoff outcomes. The bids were displayed on a screen at the front of the laboratory, listed in order from the lowest bid to the highest without identifying which participants had submitted each bid. The subjects could thus see how closely their strategies for bidding matched the optimal strategy that yielded the greatest possible earnings.

Part B of the experiment served as a transition from Part A to Part C. In Part A, participants were asked to bid on an exogenously selected cash value, which for some can be a difficult concept to understand. Part B provided a bridge between Part A and Part C so that participants could accustom themselves to implementing the BDM mechanism with a real-world object for which each person had a unique, endogenously selected value. In Part B, participants were asked to bid on a Ticonderoga-brand pencil. Part B consisted of a single round of bidding, participants were given an initial balance of $\$ 0.50$, and they were asked to bid between $\$ 0$ and $\$ 0.50$ for a pencil. Once all of the bids had been submitted, a price between $\$ 0$ and $\$ 0.49$ was determined using a new random-number table. As in Part A, if the bid was equal to or greater than the price, the participant received the pencil and its price was subtracted from her initial balance. If the bid was lower than the price, the 
participant did not receive a pencil but retained the entire initial balance of $\$ 0.50$. At the end of the round, pencils were handed out to participants whose bids were successful.

\subsection{Experiment Part C: WTP for Milk}

For Part $\mathrm{C}$ of the experiment, participants were given an initial balance of $\$ 5$ and asked to submit bids ranging from $\$ 0$ to $\$ 5$ for nine different food items that would be presented sequentially. ${ }^{5}$ Participants were told that, after submitting bids for each of the nine food items, they would learn which item and corresponding bids would be used to determine the final payout. This selection would be done randomly so subjects were advised to submit bids for each food item as if it would be the one used to determine cash earnings. This type of experiment is commonly referred to as a withinsubject design as the same subject is asked multiple questions. An advantage of within-subject designs is that they allow for direct comparisons of how the a person views different types of products and information while also naturally controlling for a variety of individual-specific observable and unobservable elements, such as confusion about the operation of the bidding mechanism or experiment procedures. For instance, if a subject consistently submits bids that exceed her true WTP due to confusion about the BDM mechanism, a within-subject design helps control the

\footnotetext{
${ }^{5}$ Unlike other experiments on food preferences, this design did not endow participants with a base product (such as conventional milk) and then assess their WTP for upgrading to another product, such as rBST-free milk. The endow-and-upgrade design was made popular by Shogren et al. (1994) but has been shown to affect WTP results in some experimental settings (Corrigan and Rousu 2006; Lusk, Feldkamp, and Schroeder 2004). However, in the case of their review of endowment biases in BDM auctions, Lusk, Feldkamp, and Schroeder (2004) pointed out that providing an endowment does not significantly affect bids in the BDM mechanism (p. 404). In this design, the "upgrade" options were not defined, especially the differences in fat type where a consumer makes a trade-off between taste and fat intake preferences, so only a positive WTP for the products was elicited.
} 
influence of this overbidding since it occurs for all of the products the participant considers. By analyzing the data with a mixed-model two-limit Tobit that clusters across the individual (as described later), this research further controls for errors resulting from receiving multiple observations from the same participant.

The nine choices of milk in Part C were presented in three flights based on production type: conventional, rBST-free, and organic (see Table 1). For each flight of milk, participants were given a three-column taste-testing template, along with three five-ounce tasting cups, each filled with the same type of milk but varying by fat content $-0 \%$ skim, $1 \%$ lowfat, and 3.25\% whole. Participants were asked to taste each cup of milk and afterwards to answer two questions regarding the quality and freshness of each sample. ${ }^{6}$ The questions asked, on a scale of one to ten, how closely the taste of the milk matched the subjects’ expectations of fresh, high-quality milk and how well they liked the milk sample overall. The taste-testing questions were based on two hedonic milk studies in which experiment participants were asked to rate their level of "like" for milk, as well as rating the intensity of various milk characteristics (Chapman and Boor 2001; Chapman, Lawless, and Boor 2001). After answering the tasting questions, participants submitted bids representing the highest amount that they would pay for a one-quart carton of this type of milk.

In the context of this research, it is of interest to compare how participants bid on the samples of milk with which they were presented in the experiment to how they would make a milk purchase decision in the real-world context of a grocery store. With the introduction of rBST-free milk in the marketplace, a typical milk consumer's set of choices expanded from eight milk varieties (conventional or organic milk and $0 \%, 1 \%, 2 \%$, or $3.25 \%$ fat) to twelve. Our experiment design focused on recreating, as much as possible, the set of products a milk consumer would consider in making a

\footnotetext{
${ }^{6}$ See Appendix 2 to view the taste-testing template.
} 
purchase decision-in this case, nine milk varieties (conventional, rBST-free, or organic milk and $0 \%, 1 \%$, and 3.25\% fat)—and then asked the subjects to bid on milk produced using a given method in isolation, without considering their WTP for milk produced using the other two methods. While the ideal experimental design would be a perfect replication of the real-world milk purchase decision (Louviere 2006), this experimental design offers several advantages. First, the experiment is aided by the familiarity of the purchase decision since the adult participants in this study had made milk purchases repeatedly over many years and are accustomed to considering the purchase of milk at different prices (such as price differences commonly observed for different container sizes or whether the milk is purchased at a grocery store, shoppers club, or convenience store) and with different characteristics (such as organic/conventional production or flavored milk).

Furthermore, to answer the question posed in this study, use of the BDM mechanism is superior to a dichotomous yes/no choice on a posted price (the setting most commonly found in marketplaces) because the BDM mechanism provides specific point estimates for a consumers' WTP for different types of milk, something that would be very costly to do with dichotomous choice as the posted prices would have to be varied over a large range of possibilities, requiring a much larger sample size. Finally, these objective bids, along with questionnaire data and data regarding the order in which the different types of milk were presented, can be combined to analyze how the introduction of rBST-free milk into the market impacted consumers' WTP for conventional milk.

To mimic the information provided in a grocery store setting, subjects were given handouts containing nutrition and production information for each flight of milk. Importantly, the nutrition information differed only by fat type and not by 
production technique. $^{7}$ The information handout for rBST-free milk included a statement that the milk "does not contain artificial growth hormones" and the handout for organic milk included a statement that the milk was "produced without the use of antibiotics, synthetic growth hormones, or pesticides.” The wording for both statements came directly from the labels on the cartons of the original milks. The information sheet for conventional milk was labeled as "conventional milk" and did not make any claims regarding the production process. In the oral protocols, participants were informed that conventional milk was the type of milk most commonly available in grocery and convenience stores. To avoid any packaging or branding effect, all nine milks were served in clear pitchers and subjects did not see the brands of milk used in the experiment.

Once all nine bids had been placed and the milk type selected, a price was drawn at random and the quarts of milk were distributed to those whose bids were successful.

\footnotetext{
${ }^{7}$ See Appendix 3 to view the nutrition information handout.
} 


\section{Chapter 4}

\section{Results}

The experimental results from 148 adult subjects support the existence of a stigma effect from both organic and rBST-free milk on conventional milk. However, when looking at average WTP for milk of a given fat type, the stigma effect - especially the one from the introduction of milk labeled rBST-free - is initially difficult to detect. For example, as seen in Table 2a, participants' average WTP was $\$ 1.03$ for skim milk produced conventionally, $\$ 1.06$ for skim milk produced without rBST, and $\$ 1.40$ for skim milk produced using organic practices; the average tasting scores for these skim milks were 4.87, 4.87, and 6.18, respectively. The stigma effect becomes apparent when the average WTP values are separated by the order in which the milks were presented. The impact of the order of presentation is shown in Figure 1. Most notable is the decrease in overall WTP for conventional milk from when it was presented first to when it was presented last (Figure 1a). When conventional milk was the first

Table 2: WTP and tasting values for milk by fat type and production method

a) $0 \%$ and $1 \%$ Milk

\begin{tabular}{|c|cc|cc|}
\hline & \multicolumn{2}{|c|}{ 0\% Milk } & \multicolumn{2}{c|}{ 1\% Milk } \\
\hline & WTP & $\begin{array}{c}\text { Difference from } \\
\text { Conventional }\end{array}$ & WTP & $\begin{array}{c}\text { Difference from } \\
\text { Conventional }\end{array}$ \\
\hline $\begin{array}{c}\text { Conventional } \\
\text { rBST-free }\end{array}$ & $\$ 1.03$ & - & $\$ 1.11$ & - \\
Organic & $\$ 1.06$ & $+\$ 0.03$ & $\$ 1.14$ & $+\$ 0.03$ \\
& Tasting & Difference from & Tasting & Difference from \\
& Score & Conventional & Score & Conventional \\
\hline Conventional & 4.87 & - & 5.76 & - \\
rBST-free & 4.87 & 0.00 & 5.56 & -0.20 \\
Organic & 6.18 & +1.31 & 6.75 & +0.99 \\
\hline
\end{tabular}




\section{Table 2 (Continued)}

b) $3.25 \%$ Milk and Overall Averages

\begin{tabular}{|c|cc|cc|}
\hline & \multicolumn{2}{|c|}{ 3.25\% Milk } & \multicolumn{2}{c|}{ Overall } \\
\hline & \multicolumn{3}{|c|}{$\begin{array}{c}\text { Difference from } \\
\text { Conventional }\end{array}$} & \multicolumn{2}{c|}{ WTP } & $\begin{array}{c}\text { Difference from } \\
\text { Conventional }\end{array}$ \\
\hline Conventional & $\$ 1.04$ & - & $\$ 1.06$ & - \\
rBST-free & $\$ 1.02$ & $-\$ 0.02$ & $\$ 1.08$ & $+\$ 0.02$ \\
Organic & $\$ 1.23$ & $+\$ 0.19$ & $\$ 1.35$ & $+\$ 0.29$ \\
\hline & Tasting & Difference from & Tasting & Difference from \\
& Score & Conventional & Score & Conventional \\
\hline Conventional & 5.60 & - & 5.41 & - \\
rBST-free & 5.45 & -0.15 & 5.30 & -0.11 \\
Organic & 6.26 & +0.66 & 6.40 & +0.99 \\
\hline
\end{tabular}

product presented, the average WTP offer was $\$ 1.28$ (Table 3). However, when conventional milk was presented last (the third of three flights), the subjects were aware of the complete set of products, had the chance to taste all of them, and, much like in a grocery store, were presented with a wide variety of milk choices. In this case, average WTP values for conventional milk fell to $\$ 0.61$ (a decline of 52.3\%). On

Table 3: Average WTP for milk by fat type, production method, and order of tasting

\section{Tasted First}

\begin{tabular}{|c|c|c|c|c|c|}
\hline & $\begin{array}{c}\text { WTP } \\
\text { Conventional } \\
\end{array}$ & $\begin{array}{l}\text { WTP } \\
\text { rBST- } \\
\text { free } \\
\end{array}$ & $\begin{array}{c}\text { Difference } \\
\text { from } \\
\text { Conventional }\end{array}$ & $\begin{array}{c}\text { WTP } \\
\text { Organic }\end{array}$ & $\begin{array}{c}\text { Difference } \\
\text { from } \\
\text { Conventional }\end{array}$ \\
\hline 0\% Skim & $\$ 1.23$ & $\$ 1.03$ & $-\$ 0.20$ & $\$ 1.53$ & $+\$ 0.20$ \\
\hline 1\% Lowfat & $\$ 1.37$ & $\$ 1.16$ & $-\$ 0.21$ & $\$ 1.39$ & $+\$ 0.02$ \\
\hline $3.25 \%$ Whole & $\$ 1.52$ & $\$ 1.24$ & $-\$ 0.28$ & $\$ 1.19$ & $-\$ 0.33$ \\
\hline All Fat Types & $\$ 1.28$ & $\$ 1.05$ & $-\$ 0.23$ & $\$ 1.37$ & $+\$ 0.09$ \\
\hline \multicolumn{6}{|c|}{ Tasted Last } \\
\hline & $\begin{array}{c}\text { WTP } \\
\text { Conventional }\end{array}$ & $\begin{array}{l}\text { WTP } \\
\text { rBST- } \\
\text { free } \\
\end{array}$ & $\begin{array}{c}\text { Difference } \\
\text { from } \\
\text { Conventional }\end{array}$ & $\begin{array}{c}\text { WTP } \\
\text { Organic }\end{array}$ & $\begin{array}{c}\text { Difference } \\
\text { from } \\
\text { Conventional }\end{array}$ \\
\hline 0\% Skim & $\$ 0.55$ & $\$ 1.14$ & $+\$ 0.59$ & $\$ 1.32$ & $+\$ 0.77$ \\
\hline 1\% Lowfat & $\$ 0.64$ & $\$ 1.22$ & $+\$ 0.58$ & $\$ 1.41$ & $+\$ 0.77$ \\
\hline $3.25 \%$ Whole & $\$ 0.63$ & $\$ 1.09$ & $+\$ 0.46$ & $\$ 1.34$ & $+\$ 0.71$ \\
\hline All Fat Types & $\$ 0.61$ & $\$ 1.15$ & $+\$ 0.54$ & $\$ 1.36$ & $+\$ 0.75$ \\
\hline
\end{tabular}


a) Conventional Milk

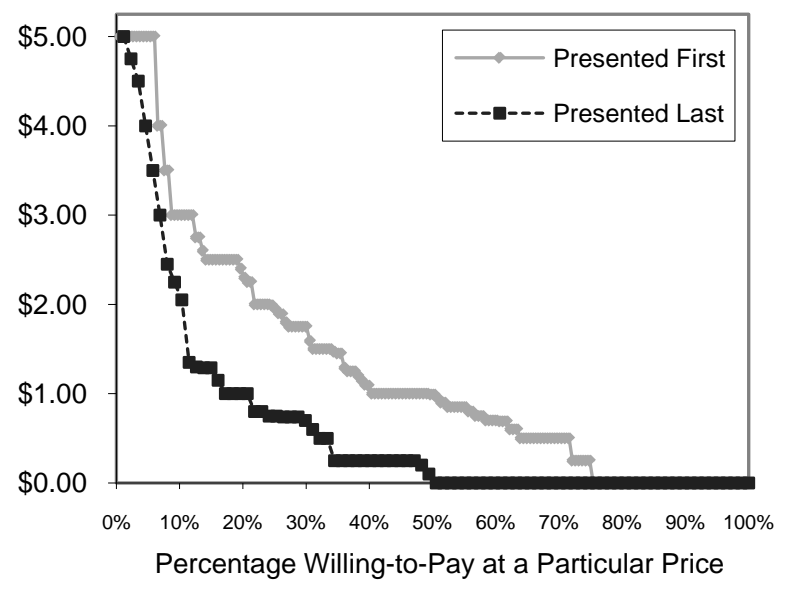

b) rBST-Free Milk

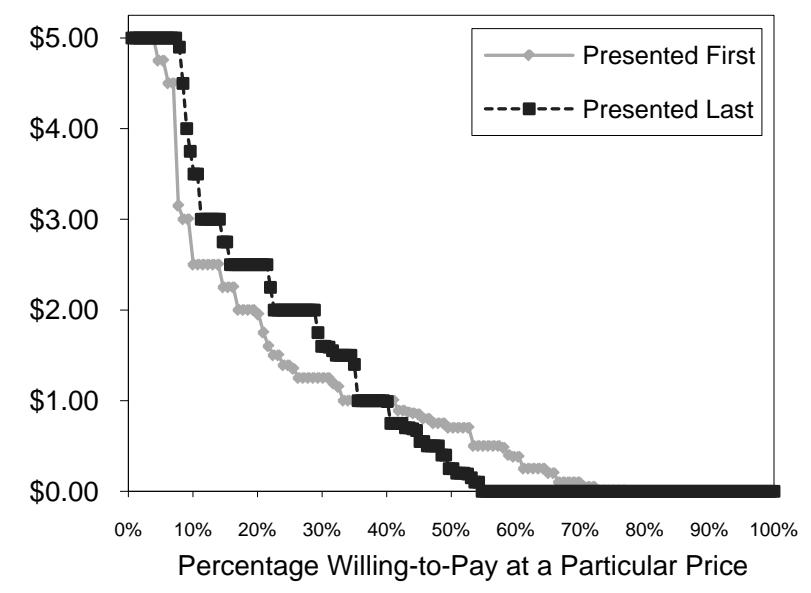

c) Organic Milk

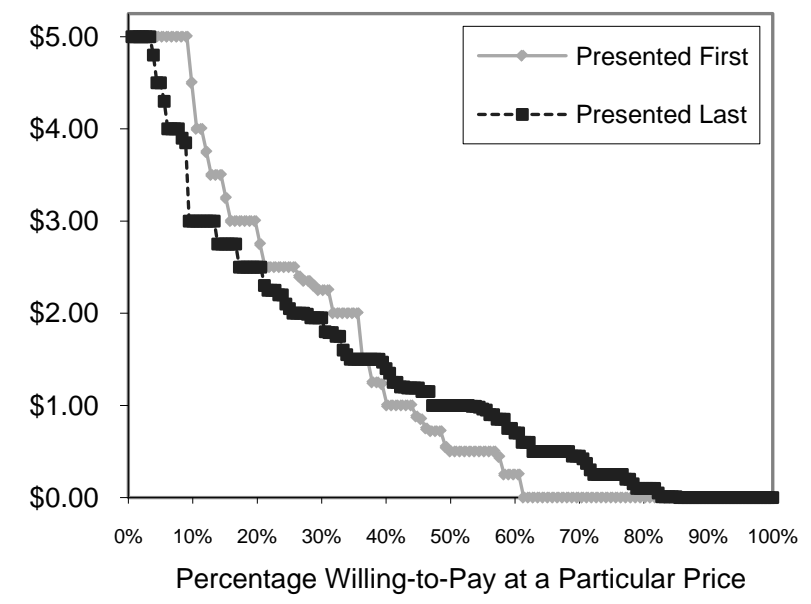

Figure 1: Percentage of subjects willing to pay at a particular price, by the order the milks were presented 
the other hand, the trend for rBST-free milk is different as the values generally increased (Figure 1b). When rBST-free milk was presented first, the mean WTP was \$1.05; when the same milk was presented last, the mean WTP increased by $9.5 \%$ to \$1.15. Organic milk saw essentially no change in WTP due to order, as mean WTP was $\$ 1.37$ when presented first and $\$ 1.36$ when presented last.

While some of the decline in WTP for conventional milk may have been anticipated since the average tasting value for conventional milk dropped $15.9 \%$ from 5.92 when presented first to 4.98 when presented last (Table 4), the decrease in perceived taste does not explain all of the decline. For example, rBST-free milk saw an even more dramatic decrease in its tasting value due to order-from 6.31 when presented first to 4.86 when presented last (a decline of 23.0\%)—even though the WTP increased by $9.5 \%^{8}$

Table 4: Average tasting values for milk by fat type, production method, and order of tasting

\section{Tasted First}

\begin{tabular}{c|ccccc}
\hline & \multicolumn{3}{|c}{$\begin{array}{c}\text { Difference } \\
\text { from } \\
\text { CosT- } \\
\text { free }\end{array}$} & $\begin{array}{c}\text { Conventional } \\
\text { Conventional }\end{array}$ & $\begin{array}{c}\text { Oifference } \\
\text { from } \\
\text { Conventional }\end{array}$ \\
\hline 0\% Skim & 5.47 & 6.00 & +0.53 & 6.45 & +0.98 \\
1\% Lowfat & 6.22 & 6.67 & +0.45 & 6.57 & +0.35 \\
3.25\% Whole & 6.07 & 6.26 & +0.19 & 5.62 & -0.45 \\
All Fat Types & $\mathbf{5 . 9 2}$ & $\mathbf{6 . 3 1}$ & $\mathbf{+ 0 . 3 9}$ & $\mathbf{6 . 2 1}$ & $\mathbf{+ 0 . 2 9}$ \\
\hline
\end{tabular}

Tasted Last

\begin{tabular}{c|ccccc}
\hline & \multicolumn{3}{|c}{$\begin{array}{c}\text { Difference } \\
\text { from } \\
\text { rBST- } \\
\text { free }\end{array}$} & $\begin{array}{c}\text { Conventional } \\
\text { Organic }\end{array}$ & $\begin{array}{c}\text { Difference } \\
\text { Conventional } \\
\text { Conventional }\end{array}$ \\
\hline 0\% Skim & 4.43 & 4.19 & -0.24 & 6.25 & +1.82 \\
1\% Lowfat & 5.07 & 5.22 & +0.15 & 6.93 & +1.86 \\
3.25\% Whole & 5.43 & 5.16 & $-\$ 0.27$ & 6.45 & +1.02 \\
All Fat Types & $\mathbf{4 . 9 8}$ & $\mathbf{4 . 8 6}$ & $\mathbf{- 0 . 1 0}$ & $\mathbf{6 . 5 4}$ & $\mathbf{+ 1 . 5 6}$ \\
\hline
\end{tabular}

\footnotetext{
${ }^{8}$ Not all of the tasting values declined with the introduction of additional milk products. For instance, the average taste values for organic milk increased from 6.21 when presented first to 6.54 when presented last.
} 
A stigma effect is also potentially present when we pool together the subjects' WTP for milk produced using all three techniques, effectively considering a single demand curve for conventionally produced, rBST-free, and organic milk. The mean WTP for all three milk types when conventional milk was presented first was $\$ 1.22$; the mean WTP when conventional milk was presented third was $\$ 0.90$ (the difference in mean WTP is statistically significant at the $1 \%$ level, $(\mathrm{p}=0.0014))$. This suggests that the introduction of milk labeled as being rBST-free or organic could have a much greater influence than simply reducing WTP for conventional milk—-the availability of rBST-free and organic milk could reduce the demand for all types of milk.

While the descriptive statistics and figures previously discussed are suggestive of a stigma effect, to evaluate formally whether this phenomenon is a result of the order, a detailed analysis of subjects' WTP is necessary. Since participants in the experiments were asked to submit bids for multiple milks with varying fat types and these bids were constrained to between $\$ 0.00$ and $\$ 5.00$, we utilized a two-limit random-effect Tobit model. To evaluate whether there is a stigma effect from milk labeled as rBST-free and organic on conventional milk, the differences in WTP for milks with the same fat content were evaluated in three different models. ${ }^{9}$

The models included dummy variables to indicate the fat content of the milk (FAT1 - 1\% lowfat milk; FAT3 - 3.25\% whole milk), whether the participant was the primary shopper in the household (PRIME_SHOP), whether the participant was aware of the availability of rBST-free (RBST_AVAIL) and organic milk (ORG_AVAIL) prior to the experiment, whether the participant was lactose intolerant (LACT_INT), and the participant's gender ( $M A L E$ ). The participants responded to questions related to the

\footnotetext{
${ }^{9}$ Censored bids (bids of $\$ 0$ or $\$ 5$ ) that did not differ between the milks with different labels were excluded from the analysis, since-given the censored nature of the data - the analysis could not determine whether there was truly a zero difference between the subjects' WTP (or willingness to accept (WTA) in the case of censored bids of \$0) for the milks or whether the change in real WTP/WTA occurred outside the range of observation.
} 
frequency with which they purchased conventional (FREQ_CONV), rBST-free (FREQ_RBST), and organic milk (FREQ_ORG) and how risky they considered milk (MILK_RISK). ${ }^{10}$ Subjects also reported the number of children under ten in the household (CHU10), the highest level of education obtained (EDUC), and income (INCOME). As a control on the participants' understanding of the BDM mechanism, a variable was included to represent their deviations from the final induced-value round during the first part of the experiment $(B D M)$. Since a participant's perceptions of the taste of a milk could have been influenced by the order in which presentation of the milks, a two-stage model was used that included estimated values for the differences in taste values (TASTE_RC, TASTE_OC, and TASTE_OR) as instrumental variables to avoid simultaneous-equation bias. ${ }^{11}$

The average values for some of these variables offer insight into the demographic breakdown of the participants. For example, 83\% identified themselves as the primary shopper for the household and household milk consumption averaged almost 1.5 gallons per week of mainly conventional milk. Awareness of organiclabeled milk in the marketplace was much greater (92\%) than was awareness of milk labeled as rBST-free (just 54\%). The average participant attended some college without earning a degree and had an annual household income of slightly more than $\$ 57,000 ; 27 \%$ of households had children under the age of ten living at home.

Most importantly for our analysis, a dummy variable was included to indicate the order in which the flights of milk were presented. Conventional milk was labeled as $C$, rBST-free milk as $R$, and organic milk as $O$. Thus, the order of presentation was indicated by the order of the letter code. For example, if rBST-free milk was presented

\footnotetext{
${ }^{10}$ The value for the risk-preference variable is the mean of the answers to four questions regarding the participants' attitudes towards the riskiness of pesticides, antibiotics, artificial hormones, and herbicides/fungicides - a higher number indicates a higher level of concern for a given risk factor. ${ }^{11}$ The explanatory variables in the analysis of the difference in taste variables were the same as those used in the general model except that the exact order of the presentation of the milk was also included.
} 
before conventional milk, the dummy variable for the session was $R C$. Likewise, if organic milk was presented before conventional milk, that session was coded as OC. By setting up the models in this manner, we were able to isolate the effect of varying the order of presentation with the order variables $-R C, O C$, and $O R$-representing the size of the stigma effect and the coefficients on the other variables representing the price premium that participants with that particular attribute would pay for the alternative milk, ceteris paribus.

Using these models, we were able to test three different hypotheses regarding how participants' WTP for milk changes as the order in which they taste flights of milk is altered. The null hypothesis in each of the cases asserts that difference in WTP for the milk does not change as the order the flights are tasted changes, while the alternative hypothesis asserts that WTP for milk varies as the order changes.

\subsection{Difference in WTP Between rBST-Free and Conventional Milk}

As seen in column (1) of Table 5, the difference in WTP when rBST-free milk is presented before conventional milk (Model 1) shows that the marginal effect coefficient $^{12}$ for the order dummy variable $R C(0.351)$ is statistically significant $(\mathrm{t}=$ 2.35, $p=0.019)$. Thus, we can reject the hypothesis that order does not affect WTP for rBST-free and conventional milk. The coefficient for $R C$ indicates that participants are willing to pay \$0.35 per quart less for conventional milk after tasting and being exposed to label information regarding rBST-free milk (i.e., rBST-free milk "does not contain any artificial growth hormones”).

\footnotetext{
${ }^{12}$ Marginal effect coefficients deflate the Tobit coefficients so that we may directly examine the marginal effect of increasing a given dependent variable one unit. We cannot make this comparison with the normal Tobit coefficients.
} 
Table 5: Two-limit, random-effect tobit model of differences between WTP

\begin{tabular}{|c|c|c|c|c|c|c|}
\hline \multirow[b]{2}{*}{ Variable } & \multicolumn{2}{|c|}{$\begin{array}{c}\text { (1) rBST-Free - } \\
\text { Conv. }\end{array}$} & \multicolumn{2}{|c|}{ (2) Organic - Conv. } & \multicolumn{2}{|c|}{$\begin{array}{l}\text { (3) Organic - } \\
\text { rBST-Free }\end{array}$} \\
\hline & Coeff. & Std. Error & Coeff. & Std. Error & Coeff. & Std. Error \\
\hline CONSTANT & $-4.850 * *$ & $(-1.033)$ & $-2.448^{*}$ & $(-1.011)$ & 0.406 & $(-1.339)$ \\
\hline$R C$ & $0.351^{*}$ & $(-0.149)$ & & & & \\
\hline$O C$ & & & $0.482 * *$ & $(-0.163)$ & & \\
\hline OR & & & & & 0.024 & $(-0.165)$ \\
\hline TASTE_RC & $0.125^{* *}$ & $(-0.032)$ & & & & \\
\hline TASTE_OC & & & 0.051 & $(-0.062)$ & & \\
\hline TASTE_OR & & & & & 0.009 & $(-0.063)$ \\
\hline FAT1 & 0.024 & $(-0.679)$ & -0.029 & $(-0.084)$ & -0.042 & $(-0.078)$ \\
\hline FAT3 & 0.019 & $(-0.072)$ & -0.112 & $(-0.125)$ & -0.112 & $(-0.096)$ \\
\hline FREQ_CONV & $0.166^{*}$ & $(-0.072)$ & -0.029 & $(-0.079)$ & -0.091 & $(-0.069)$ \\
\hline FREQ_RBST & $0.201 *$ & $(-0.090)$ & 0.129 & $(-0.103)$ & 0.122 & $(-0.110)$ \\
\hline FREQ_ORG & 0.146 & $(-0.077)$ & 0.011 & $(-0.074)$ & -0.076 & $(-0.077)$ \\
\hline PRIME_SHOP & $1.019 * * *$ & $(-0.296)$ & 0.507 & $(-0.305)$ & 0.277 & $(-0.300)$ \\
\hline RBST_AVAIL & 0.256 & $(-0.153)$ & 0.218 & $(-0.191)$ & 0.087 & $(-0.171)$ \\
\hline ORG_AVAIL & -0.334 & $(-0.238)$ & -0.43 & $(-0.247)$ & -0.497 & $(-0.283)$ \\
\hline MILK_RISK & $0.078 * *$ & $(-0.027)$ & $0.096^{* *}$ & $(-0.030)$ & $0.079 * *$ & $(-0.031)$ \\
\hline$M A L E$ & $0.393^{*}$ & $(-0.172)$ & 0.200 & $(-0.183)$ & 0.133 & $(-0.187)$ \\
\hline CHU10 & -0.063 & $(-0.106)$ & -0.068 & $(-0.108)$ & -0.098 & $(-0.111)$ \\
\hline EDUC & $0.083^{*}$ & $(-0.040)$ & 0.058 & $(-0.055)$ & -0.023 & $(-0.045)$ \\
\hline INCOME & 3.01E-06 & $(-1.92 \mathrm{E}-06)$ & $-6.40 \mathrm{E}-07$ & $(-1.97 \mathrm{E}-06)$ & 3.04E-08 & $(-2.43 \mathrm{E}-06)$ \\
\hline$B D M$ & $0.394 *$ & $(-0.161)$ & 0.321 & $(-0.178)$ & 0.157 & $(-0.177)$ \\
\hline LACT_INT & 0.256 & $(-0.199)$ & 0.111 & $(-0.223)$ & -0.212 & $(-0.201)$ \\
\hline Log Likelihood & -271.3 & & -317.0 & & -322.8 & \\
\hline Wald $\chi^{2}$ & 65.74 & & 68.9 & & 25.01 & \\
\hline Prob > chi2 & 0 & & 0 & & 0.095 & \\
\hline \# of Uncensored & 282 & & 294 & & 294 & \\
\hline $\begin{array}{l}\text { \# of Left- } \\
\text { censored }\end{array}$ & 0 & & 0 & & 0 & \\
\hline $\begin{array}{l}\text { \# of Right- } \\
\text { censored }\end{array}$ & 1 & & 3 & & 2 & \\
\hline
\end{tabular}

Note: Significance is indicated by * for the $5 \%$ level and ${ }^{* *}$ for $1 \%$ level or less. 
Several other variables besides the order dummy variable bear mentioning. The instrumental variable representing the difference in taste perception between rBST-free and conventional milk (TASTE_RC) is statistically significant, indicating the intuitive behavioral response that participants who thought that rBST-free milk of a given fat type tasted better than the conventional version of the same fat type were willing to pay more for it. Additionally, the more frequently a participant consumes either conventional or rBST-free milk (FREQ_CONV and FREQ_RBST), the larger the difference in WTP between rBST-free and conventional milk as both coefficients are positive and significant at the 0.05 level or better. Also, the coefficient on the variables related to whether the participant is the primary shopper (PRIME_SHOP) is large, a \$1.11 difference for a quart of milk, and statistically significant at the 0.01 level. This suggests that the household member who normally does the shopping is typically willing to pay more of a premium for rBST-free milk than those who do not. Importantly, these results imply that the stigma effect is not a phenomenon of naive and infrequent consumers but is something exhibited by experienced consumers of milk.

Participants who expressed concern about the riskiness of milk (MILK_RISK) were willing to pay a higher premium for rBST-free milk, as were those who had more education (EDUC) and those who bid higher than the induced value in the last practice round of the BDM mechanism.

\subsection{Difference in WTP Between Organic and Conventional Milk}

Column (2) in Table 5 shows the results of the model that uses the difference in WTP for organic and conventional milk as the dependent variable. This model again shows 
a stigma effect on WTP for conventional milk when it is presented after organic milk. In this case, the coefficient for the variable $O R$ is even larger (0.482) and statistically significant at the 0.01 level $(p=0.003)$. Thus, we can also reject the hypothesis that order does not affect WTP for organic and conventional milk. Subjects are willing to pay $\$ 0.48$ per quart less for conventional milk after tasting and being exposed to label information regarding organic milk (i.e., organic milk "produced without the use of antibiotics, synthetic growth hormones, or pesticides”). The larger stigma effect of organic compared with rBST-free milk on conventional milk is intuitive since organic milk is free of more than rBST, having additional claims of being pesticide and antibiotic free.

Additionally, the variable measuring the participants’ perceptions of the risks involved with consuming milk (MILK_RISK) was highly significant $(p=0.001)$ and had a positive coefficient (0.096). At the same time, several factors that are significant in the regression of WTP for rBST-free and conventional milk are not significant in this model. This could in part be driven by the higher level of preexisting information participants possessed regarding organic milk compared to rBST-free (92\% were aware of organic milk while 54\% were aware of rBST-free milk). Subjects who are willing to pay a high premium for organic milk likely are consumers who are already aware of its availability and reputation as a "safe" alternative to conventional milk. Hence, perception of the risks involved with consuming milk is a key factor in determining the price premium for organic milk. 


\subsection{Difference in WTP Between Organic and rBST-Free Milk}

Column (3) in Table 5 shows the results of the model for the difference in WTP for organic and rBST-free milk, with no significant difference in WTP based on the order of presentation (OR). Thus, we fail to reject the hypothesis that order does not affect WTP for organic and rBST-free milk. It is important to note that rejection of the null hypothesis does not indicate that participants were willing to pay the same amount for organic and rBST-free milk, only that the difference in WTP was not caused by the order of presentation.

The only variable that is statistically significant at the 0.05 level is the perception of milk risk (MILK_RISK), which had a positive coefficient (0.079). This indicates that participants view organic milk as a safer product than milk that is only rBST-free, likely due to the labels, which indicate that organic milk is produced without the use of antibiotics and pesticides. 


\section{Chapter 5}

\section{Conclusion}

The economic implications of the stigmatization of goods have not been thoroughly examined in the literature. Producers of conventional items have frequently been concerned about the negative consequences that may result from the introduction of new, similar products with labels touting better production methods, such as birdfriendly coffee, free-range chicken, sustainably harvested wood, and a variety of products marketed under the label of fair trade.

In the dairy industry, the use of recombinant bovine somatotropin (rBST), a synthetic version of a naturally occurring hormone, with milk-producing cows is an example of how stigma effects can have economic repercussions for the conventional product. The objective of this research was to determine whether the introduction of rBST-free and organic milk has a stigma effect on conventional milk. The question was addressed using experimental economics and by eliciting WTP measures from adult subjects for milk produced via different methods and varying in fat content. The advantage of using an experimental setting is the ability to observe directly the behavior of participants making actual purchase decisions as opposed to using survey techniques to pose hypothetical questions. The stigma effect was measured by altering the order in which participants were introduced to and asked to bid for the different types of milk.

The results of this study of 148 adult subjects indicate a substantial stigma effect from both organic and rBST-free milk on conventional milk. To measure the stigma effect, differences in WTP for milks with the same fat content were evaluated in three different models. Using a two-limit random-effect Tobit model to control for 
other factors affecting the difference in WTP, we find negative and statistically significant marginal effects for the coefficients on the variable measuring the stigma effect from organic on conventional milk and from rBST-free on conventional milk. Specifically, participants were willing to pay, on average, \$0.35 per quart less for conventional milk after tasting and being exposed to information regarding rBST-free milk (i.e., rBST-free milk “does not contain any artificial growth hormones”). This represents a 33\% reduction in WTP for conventional milk based on the overall average WTP in our study (\$1.06 per quart). There was an even stronger stigma effect from organic milk; participants were willing to pay, on average, $\$ 0.48$ per quarter less for conventional milk after tasting and being exposed to information regarding organic milk (i.e., organic milk "produced without the use of antibiotics, synthetic growth hormones, or pesticides”). This represents a 45\% reduction in WTP for conventional milk.

These results suggest that participants view conventional milk more negatively after the introduction of rBST-free and organic milk. This finding supports the idea that conventional milk becomes a stigmatized good after rBST-free and organic milk are introduced into the marketplace.

These results also indicate that all milk types (conventional, rBST-free, and organic) are stigmatized by the introduction of rBST-free and organic milk. The mean WTP for all three milk types when conventional milk was presented first was $\$ 1.22$; the mean WTP when conventional milk was presented third was $\$ 0.90$. This $\$ 0.32$ difference (26\%) was statistically significant at the 0.014 level. This finding suggests that the introduction of milk labeled as being rBST-free or organic could have a much greater influence than simply reducing WTP for conventional milk. That is, the introduction of rBST-free and organic milk could potentially reduce the demand for all types of milk. 
A caveat on these results should be noted. Our findings are based on observations from a laboratory experiment, which is not identical to real marketplace conditions. In particular, the introduction of organic and rBST-Free milk products in the real market occurred gradually over a substantially longer time period than was modeled in our experiment. Given the rapid, sequential introduction of all three product types in our experiment, our results likely represent a short-term measurement of the stigma effect. Further research into how long this stigma effect lasts is thus warranted.

The experimental results illustrate that the recent actions by Wal-Mart, Dean Foods, and Starbucks to ban conventional milk and supply only rBST-free (and organic) milk may have significant negative consequences for conventional milk demand. The implication of the stigma effect found here is that the dairy industry will have to confront this issue head-on or risk a possibly major negative impact on milk consumption. 
APPENDIX

APPENDIX 1: EXPERIMENT INSTRUCTIONS

\section{$\underline{\text { Instructions - (Part A) }}$}

Welcome to an experiment in the economics of decision making. In the course of the experiment, you will have opportunities to earn money. Any money earned during this experiment is yours to keep, thus please read these instructions carefully. Additionally, you are guaranteed a $\$ \mathbf{5 . 0 0}$ show-up fee for participating, regardless of what you may earn during the experiment. Please do not communicate with other participants during the experiment. As stated in the Consent Form, your participation in this experiment is voluntary.

In today's experiment, you will be asked to indicate the highest amount of money you would pay for different purchase decisions. We will refer to this amount as your bid. Sometimes a purchase decision will refer to a cash value and sometimes it will refer to a food item.

For the first several purchase decisions, the experiment proceeds as follows:

First, you will receive an initial balance of $\$ 5$. You will then be informed of your cash value that you would receive if you purchase the decision. Your cash values will vary during the course of the experiment. The possible amounts are $\$ 1, \$ 2.50$, and $\$ 4$.

You will then be asked to indicate the highest amount that you would pay for this purchase decision. For each decision, you can bid any amount between $\$ 0$ and your initial balance of $\$ 5$. Once you have decided your bid, you will type it into the computer spreadsheet, hit ENTER on the keyboard, and then click the "Submit" 
button. After everyone has submitted their bids, the price for the purchase decision will be determined.

The price will be determined by having a volunteer subject drop a pen onto a random number table. Since these numbers have been generated by a random number table each price between $\$ 0.00$ and $\$ 5.00$ is equally likely. Whether the decision is purchased depends on your bid and the randomly determined price. There are two possible outcomes:

\section{The decision is PURCHASED: The decision is purchased if your bid is equal to or} greater than the price. In this case, you will receive the cash value in addition to your initial balance of $\$ 5$. However, you will also have to pay the randomly determined price. Therefore, your earnings would be your initial balance, plus your cash value, minus the price.

\section{The decision is NOT PURCHASED: The decision is not purchased if your bid is}

less than the price. In this case, you will not receive the cash value, but you will not have to pay the price. Therefore, your earnings would simply be your initial balance of $\$ 5$.

In this setting, it is in your best interest (i.e. you will make the most possible earnings) if you submit bids equal to your cash value for the decision. Note that while your bid helps determine whether the decision is purchased, your earnings are calculated based on your initial balance, the cash value and the determined price (not your bid). For example, if a decision was not purchased and the cash value was \$2.50 and the determined price was $\$ 4.50$, your earnings would still be $\$ 5$. However, if the decision 
was purchased with the same cash value and price, your earnings would be \$3 (=\$5 + $\$ 2.50$ - \$4.50).

Example 1.

Outcome Initial Balance Cash Value Price Earnings

Purchased $\$ 5.00$ $\$ 2.50$ $-\$ 4.50$

$\$ 3.00$

Not Purchased

$\$ 5.00$

$\$ 2.50$

$-\$ 4.50$

$\$ 5.00$

Consider another example where the cash value was \$5 and the determined price was \$1. In this example if the decision was not purchased your earnings would again be $\$ 5$, while if the decision was purchased, your earnings would be $\$ 5.50$ (\$5 + \$2.50 \$1).

Example 2.

\begin{tabular}{lcccc} 
Outcome & Initial Balance & Cash Value & Price & Earnings \\
\hline Purchased & $\$ 5.00$ & $\$ 2.50$ & $-\$ 1.00$ & $\$ 6.50$ \\
Not Purchased & $\$ 5.00$ & $\$ 2.50$ & $-\$ 1.00$ & $\$ 5.00$
\end{tabular}

\section{Calculation of Earnings}

After everyone has submitted their bids for the decision and the price has been determined, the administrator will display all of the bids on the screen in the front of the room. These bids will be displayed anonymously from lowest to highest and no subject numbers will be associated with these bids. The administrator will then ask all the participants the following questions:

1) Can you identify your bid?

2) Which subjects purchased the decision? 
3) How much will these subjects have to pay and how much will they earn in this round?

4) How much will the subjects who did not purchase the decision earn in this round?

Then you will be asked to click the RECEIVE button and the computer will display whether you purchased the decision and calculate your earnings. The computer will add your experimental earnings for all of the rounds, and convert this amount to US dollars by applying an exchange rate of 2 experimental dollars to \$1 USD. For example, if you earn 20 experimental dollars, your monetary payoff from this part of the experiment would be $\$ 10$ USD. 


\section{Instructions - Part B}

\section{Pencil as the Purchase Decision}

You will be asked to indicate the highest amount of money you would pay for a pencil using the same procedures as discussed previously. In this case, your starting balance will be $\$ 0.50$ and you can submit any bid between $\$ 0$ and $\$ 0.50$. The random price will again be determined using a random numbers table, however, now the price will range from $\$ 0.00$ to $\$ 0.50$. In this part, there will not be an exchange rate as one experimental dollar will equal \$1 USD.

Note that in the case, you will need to determine the "highest amount" that you would pay to purchase this pencil. Again, it is in your best interest to submit a bid equal to this highest amount, since, if you purchase the pencil, you will pay the randomly determined price not your bid. The two possible outcomes are as follows:

\section{The pencil is PURCHASED: The pencil is purchased if your bid is equal to or} greater than the price. In this case, you will receive the pencil in addition to your initial balance of $\$ 0.50$. However, you will also have to pay the randomly determined price.

\section{The pencil is NOT PURCHASED: The pencil is not purchased if your bid is less}

than the price. In this case, you will not receive the pencil, but you will not have to pay the price. Therefore, your cash earnings would simply be $\$ 0.50$.

After everyone has submitted their bids and the price is determined, the administrators will distribute the pencils to the subjects which purchased them. 


\section{$\underline{\text { Instructions }-(\text { Part C) }}$}

The procedures are similar to the ones used in Part B of the experiment, with some important differences.

You will receive an initial balance of $\$ 5$. The purchase decision is one quart of milk. One quart of milk is equal to one-quarter gallon, or 32 fluid ounces. The milk is cold and fresh and is being stored in the refrigerator in the lab.

You will be making a total of nine purchase decisions regarding milk. However, only one of the nine milk types will be selected for implementation and will result in cash earnings. The type of milk that will be selected for implementation has been randomly determined prior to the experiment and this information has been placed in a dated, sealed envelope that will be opened at the end of the experiment. Each of the milk types is equally likely to be implemented. Therefore consider each decision as if it is the one that will be actually implemented.

You will be served a series of three flights of milk that you will be invited to taste. Each flight of milk consists of three different milk types. The milks will be placed a tasting sheet that provides information related to the milk you will be tasting.

After sampling each milk type, please complete the questions related to the milk you tasted and then submit a bid for each of the milks. Again, your bid should represent the highest amount that you would be willing to buy that one-quart of milk today. You may bid any amount between $\$ 0$ and $\$ 5$ for each milk type. The price for the decision will be determined in the same manner as in Part A using a new random number table. 
There are two possible outcomes:

The milk is PURCHASED: The carton of milk is purchased if your bid is equal to or greater than the price. In this case, you will receive the carton of milk in addition to your initial balance of $\$ 5$. However, you will also have to pay the randomly determined price.

The milk is NOT PURCHASED: The carton of milk is not purchased if your bid is less than the price. In this case, you will not receive the carton of milk, but you will not have to pay the price. Therefore, your cash earnings would simply be $\$ 5$.

Please do not submit your bid until instructed by the administrator.

In the event that the milk is purchased, you may either take it with you immediately, or store it in the lab until the end of the day. Milk that is stored in the lab may be picked up between 4 p.m. and 5 p.m.

It is important that you clearly understand these instructions. Please raise your hand if you have any questions. Please do not talk with other participants in the experiment 


\section{APPENDIX 2: TASTING}

TEMPLATE

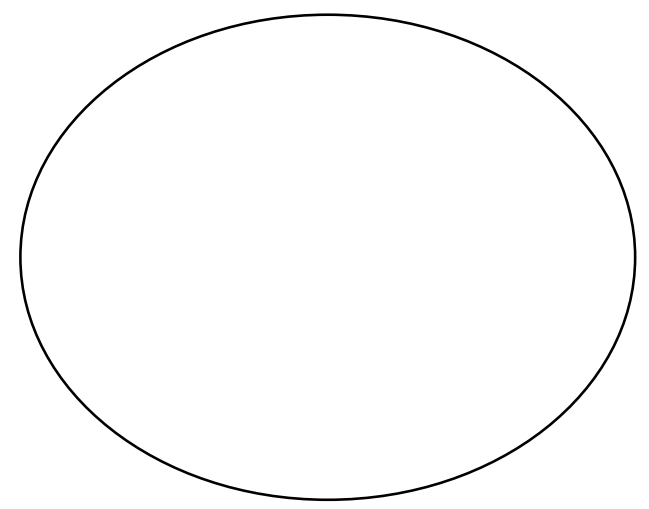

0\%MILK (Skim)

1) Please rate how closely this product matches your expectation of fresh, high quality milk $(1=$ Worse than Expected; 5 = Meets

Expectations; $10=$ Better than Expected).

\section{Worse than \\ Expected}

$$
\begin{array}{llllllllll}
1 & 2 & 3 & 4 & 5 & 6 & 7 & 8 & 9 & 10
\end{array}
$$

2) Please rate how much you like this product (from 1-10, with 10 being most favorable)
Least
Most
Favorable
Favorable

123

$\begin{array}{llllllll}3 & 4 & 5 & 6 & 7 & 8 & 9 & 10\end{array}$

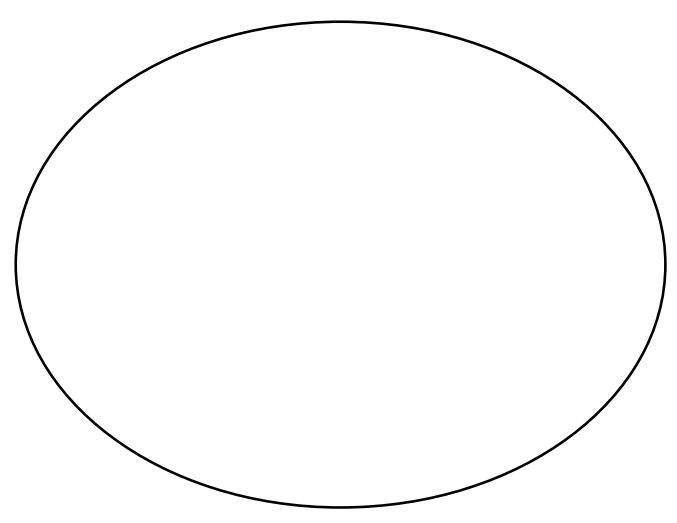

\section{1\%MILK (Low Fat)}

1) Please rate how closely this product matches your expectation of fresh, high quality milk

(1 = Worse than Expected; 5 = Meets

Expectations; 10 = Better than Expected).

\section{Worse than \\ Expected}

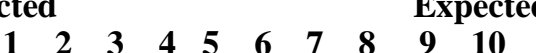

2) Please rate how much you like this product (from 1-10, with 10 being most favorable)

\section{Least}

Favorable

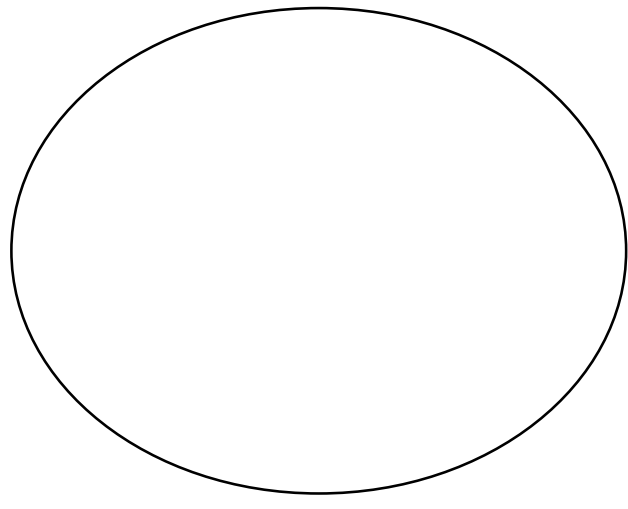

$3.25 \%$ MILK (Whole)

1) Please rate how closely this product matches your expectation of fresh, high quality milk

( 1 = Worse than Expected; 5 = Meets

Expectations; 10 = Better than Expected).

\section{Worse than}

Expected

Better than

$\begin{array}{lllllllll}1 & 2 & 3 & 4 & 5 & 6 & 7 & 8 & 9\end{array}$

2) Please rate how much you like this product (from 1-10, with 10 being most favorable)

Least

Most

Favorable

Favorable 


\author{
APPENDIX 3: NUTRITION \\ INFORMATION
}

\title{
Nutrition Information
}

\section{Nutrition Information: 0\% Fat (Skim)}

Serving Size:

Calories:

Calories from Fat:

1 cup (240 mL)

$$
90
$$$$
0
$$

$\omega$

\% Daily Value*

Total Fat:
Saturated Fat:

Trans Fat:

Cholesterol:

Sodium:

Carbohydrate:

Dietary Fiber:

Sugar:

Protein:

Vitamin A:

Calcium:

Vitamin D:

Vitamin C:

Iron:

*\% Daily Values are based on a 2000 calorie diet

Ingredients: Fat Free Milk, Vitamin A Palmitate, Vitamin D3 added.

\section{Nutrition Information: 1\% Fat (Lowfat)}

Serving Size:

Calories:

Calories from Fat:

1 cup $(240 \mathrm{~mL})$

$100-110$

20

\% Daily Value*

Total Fat:

Saturated Fat:

Trans Fat:

Cholesterol:

Sodium:

Carbohydrate:

Dietary Fiber:

Sugar:

Protein:

Vitamin A:

Calcium:

Vitamin D:

Vitamin C:

Iron:

$\begin{array}{ll}2-2.5 \mathrm{~g} & 3-4 \% \\ 1-1.5 \mathrm{~g} & 5-8 \% \\ 0 \mathrm{~g} & \\ 10-15 \mathrm{mg} & 3-4 \% \\ 125-130 \mathrm{mg} & 5 \% \\ 11-13 \mathrm{~g} & 4 \% \\ 0 \mathrm{~g} & 0 \% \\ 11-12 \mathrm{~g} & \\ 8 \mathrm{~g} & 16 \% \\ & 10 \% \\ & 30 \% \\ & 25 \% \\ & 2-4 \% \\ & 0 \%\end{array}$

*\% Daily Values are based on a 2000 calorie diet

Ingredients: 1\% Lowfat Milk, Vitamin A Palmitate, Vitamin D3 added.

\section{Nutrition Information: 3.25\% Fat (Whole)}

\begin{tabular}{lll} 
Serving Size: & $1 \mathrm{cup}(240 \mathrm{~mL})$ \\
Calories: & 150 & \\
Calories from Fat: & 70 & \\
& & \\
\% Daily Value* & & \\
Total Fat: & $8 \mathrm{~g}$ & $12 \%$ \\
Saturated Fat: & $5 \mathrm{~g}$ & $25 \%$ \\
Trans Fat: & $0 \mathrm{~g}$ & \\
Cholesterol: & $30-35 \mathrm{mg}$ & $10-11 \%$ \\
Sodium: & $120-125 \mathrm{mg}$ & $5 \%$ \\
Carbohydrate: & $11-12 \mathrm{~g}$ & $4 \%$ \\
Dietary Fiber: & $0 \mathrm{~g}$ & $0 \%$ \\
Sugar: & $11-12 \mathrm{~g}$ & \\
Protein: & $8 \mathrm{~g}$ & $16 \%$ \\
Vitamin A: & \multicolumn{2}{c}{$4 \%$} \\
Calcium: & & $30 \%$ \\
Vitamin D: & & $25 \%$ \\
Vitamin C: & & $4 \%$ \\
Iron: & & $0 \%$
\end{tabular}

*\% Daily Values are based on a 2000 calorie diet Ingredients: Milk, Vitamin D3 added. 
APPENDIX 4: POST-EXPERIMENT QUESTIONNAIRE

\section{Post-Experiment Questionnaire}

Note: Please make sure to complete the questionnaire before leaving the lab.

1. How thirsty were you during the experiment?

$$
\text { Not Thirsty 1----2----3----4----5----6----7----8----9 Very Thirsty }
$$

2. In the typical week, approximately how much milk does your household consume?

$$
\text { gallons } \quad(1 \text { quart }=1 / 4 \text { gallon })
$$

3. How often does your household drink:

$\begin{array}{llllll}\text { Conventional Milk: } & \text { Never } & \text { Rarely } & \text { Sometimes } & \text { Often } & \text { Always } \\ \text { RBST-Free Milk: } & \text { Never } & \text { Rarely } & \text { Sometimes } & \text { Often } & \text { Always } \\ \text { Organic Milk: } & \text { Never } & \text { Rarely } & \text { Sometimes } & \text { Often } & \text { Always }\end{array}$

4. $\quad$ Are you the primary shopper in your household? $\square$ Yes $\quad \square$ No

5. Including yourself, how many people live in your household? people

6. Including yourself, does anyone in your household have any milk allergies or lactose intolerance?
$\square$ Yes
$\square$ No 
7. Before today, were you aware of the availability of rBST-Free milk?

$\square$ Yes $\quad \square$ No

8. Before today, were you aware of the availability of organic milk?

$\square$ Yes $\quad \square$ No

9. How concerned are you about the following in your milk?

Pesticides:

Not Concerned

Very Concerned

Antibiotics:

1----2----3-----4----5-----6----7----8----9

Artificial Hormones:

1----2----3----4----5----6----7----8----9

Herbicides/Fungicides:

1----2----3----4----5-----6----7----8----9

1----2----3-----4----5-----6----7----8----9

10. What is your country of origin? $\square$ U.S. $\square$ Other

11. What is your gender? $\square$ Female $\square$ Male

12. Do you have children? $\square$ Yes $\square$ No

If yes, how many children live at home?

What are their ages?

13. What is your highest level of education obtained?
Some High School
High School Degree
Some College
$\square$ College Degree
$\square$ Graduate Work
Other (please
list)

14. What is your annual household income?

$\begin{array}{lll}\square \text { \$0-\$10,000 } & \square \text { \$10,001-\$20,000 } & \square \$ 20,001-\$ 30,000 \\ \square \text { \$30,001-\$40,000 } & \square \$ 40,001-\$ 50,000 & \square \$ 50,001-\$ 60,000\end{array}$




$\square$ \$60,001-\$70,000 $\square$ \$70,001-\$80,000 $\square$ \$80,001-\$90,000
$\square$ \$90,001-100,000 $\square$ \$100,001-\$110,000 $\square$ \$110,001-\$120,000
$\square$ \$120,001-\$130,000 $\square$ \$130,001-\$140,000 $\square$ \$140,001-\$150,000
$\square$ more than $\$ 150,000$

15. How risky do you consider drinking conventional milk?

Not Risky 1----2-----3----4-----5----6----7----8----9 Very Risky 


\section{REFERENCES}

Adams, G., and R. Cantor. 2001. "Risk, Stigma, and Property Value-What Are People Afraid Of?” Risk, Media and Stigma: Understanding Public Challenges to Modern Science and Technology. J. Flynn, P. Slovic, and H. Kunreuther, eds. Sterling VA: Earthscan Publications Ltd, pp. 175-186.

Barham, B., J.D. Foltz, S. Moon, and D. Jackson-Smith. 2004. “A Comparative Analysis of Recombinant Bovine Somatotropin across Major U.S. Dairy Regions.” Review of Agricultural Economics 26:32-44.

Becker, G.M., M.H. DeGroot, and J. Marschak. 1964. “Measuring Utility by a SingleResponse Sequential Method.” Behavior Science 9:226-232.

Bernard, J.C., and D.J. Bernard. In press. "What Is It about Organic Milk? An Experimental Analysis.” American Journal of Agricultural Economics.

Bernard, D.J., and A. Mathios. 2005. "Factors Affecting Consumer Choice and Willingness to Pay for Milk Attributes.” Selected paper at the American Agricultural Economics Association annual meeting, Providence RI.

Chapman, K.W., and K.J. Boor. 2001. “Acceptance of 2\% Ultra-pasteurized Milk by Consumers 6 to 11 Years Old.” Journal of Dairy Science 84:951-954.

Chapman, K.W., H.T. Lawless, and K.J. Boor. 2001. “Quantitative Descriptive Analysis and Principal Component Analysis for Sensory Characterization of Ultra Pasteurized Milk.” Journal of Dairy Science 84:12-20.

Corrigan, J.R., and M.C. Rousu. 2006. “The Effect of Initial Endowments in Experimental Auctions.” American Journal of Agricultural Economics 88:448-457. 
Dale, L., J.C. Murdoch, M.A. Thayer, and P.A. Waddell. 1999. “Do Property Values Rebound from Environmental Stigmas? Evidence from Dallas.” Land Economics 75:311-326.

Dhar, T., and J.D. Foltz. 2005. "Milk by Any Other Name . . Consumer Benefits from Labeled Milk.” American Journal of Agricultural Economics 87:214228.

Fallert, R., T. McGuckin, C. Betts, and G. Bruner. 1987. bST and the Dairy Industry: A National, Regional, and Farm Level Analysis. Washington DC: U.S. Department of Agriculture, Economic Research Service.

Forbes, B. 2008. “Loss of Milk Production Booster Could Cost Dairy Farmers, Consumers.” Purdue News Service, Purdue University, 31 January. Available at http://news.uns.purdue.edu/x/2008a/080131SchutzMilk.html.

Fox, J.A., D.J. Hayes, and J.F. Shogren. “Consumer Preferences for Food Irradiation: How Favorable and Unfavorable Descriptions Affect Preferences for Irradiated Pork in Experimental Auctions.” The Journal of Risk and Uncertainty 24(2002):75-95.

Guntermann, K.L. 1995. "Sanitary Landfills, Stigma and Industrial Land Values.” Journal of Real Estate Research 10:531-542.

Hayes, D.J., J.F. Shogren, S.Y. Shin, and J.B. Kliebenstein. "Valuing Food Safety in Experimental Auction Markets.” American Journal of Agricultural Economics 77(1995):40-53.

Horowitz, J.K. 2006. “The Becker-DeGroot-Marschak Mechanism Is Not Necessarily Incentive Compatible, Even for Non-Random Goods.” Economics Letters 93:6-11. 
Irwin, J.R., G.H. McClelland, M. McKee, W.D. Schulze, and N.E. Norden. 1998. “Payoff Dominance vs. Cognitive Transparency in Decision Making.” Economic Inquiry 36:272-285.

Kaiser, H.M., C.W. Scherer, and D.M. Barbano. 1992. “Consumer Perceptions and Attitudes toward Bovine Somatotropin.” Northeastern Journal of Agricultural and Resource Economics 21:10-20.

Karni, E., and Z. Safra. 1987. “ ' Preference Reversal’ and the Observability of Preferences by Experimental Methods.” Econometrica 55:675-685.

Louviere, J. 2006. “What You Don’t Know Might Hurt You: Some Unresolved Issues in the Design and Analysis of Discrete Choice Experiments.” Environmental \& Resource Economics 34:173-188.

Lusk, J., T. Feldkamp, and T. Schroeder. 2004. "Experimental Auction Procedure: Impact on Valuation of Quality Differentiated Goods.” American Journal of Agricultural Economics 86:389-405.

Martin, A. 2007. “Consumers Won’t Know What They’re Missing.” New York Times, 11 November. Available at www.nytimes.com/2007/11/11/business/11feed.html.

McGuckin, J.T., and S. Ghosh. 1989. “Biotechnology, Anticipated Productivity Increases, and U.S. Dairy Policy.” North Central Journal of Agricultural Economics 11:277-288.

McGuirk, A.M., and H.M. Kaiser. 1991. “bST and Milk: Benefit or Bane?” Choices, first quarter:20-26.

Messer, K.D., W.D. Schulze, K.F. Hackett, T. Cameron, and G. McClelland. 2006. “Can Stigma Explain Large Property Value Losses? The Psychology and Economics of Superfund.” Environmental and Resource Economics 33:299_ 324. 
Messer, K.D., H.M. Kaiser, C. Payne, and B. Wansink. In Press. “Measuring the Impact of Media Information about Mad Cow Disease on Consumers’ Willingness-to-Pay and Risk Attitudes” Applied Economics.

Noussair, C., S. Robin, and B. Ruffieux. 2004. “Do Consumers Really Refuse to Buy Genetically Modified Food?” The Economic Journal 114:102-120.

Rozin, P. 2004. “Technological Stigma: Some Perspectives from the Study of Contagion.” Risk, Media, and Stigma: Understanding Public Challenges to Modern Science and Technology. J. Flynn, P. Slovic, and H. Kunreuther, eds. Sterling VA: Earthscan Publications Ltd, pp. 31-40.

Rozin, P., L. Millman, and C. Nemeroff. 1986. “Operation of the Laws of Sympathetic Magic in Disgust and Other Domains.” Journal of Personality and Social Psychology 50:703-712.

Shogren, J.F., S. Shin, D.J. Hayes, and J.B. Kliebenstein. 1994. “Resolving Differences in Willingness to Pay and Willingness to Accept.” American Economic Review 84:255-270.

Tauer, L., and H.M. Kaiser. 1991. “Optimal Dairy Policy with Bovine Somatotropin.” Review of Agricultural Economics 13:1-17.

Viscusi, W.K. “Alarmist Decisions with Divergent Risk Information.” The Economic Journal 107(1997):1657-1670. 


\title{
DOES PRODUCTION LABELING STIGMATIZE CONVENTIONAL MILK?
}

\author{
A Thesis \\ Presented to the Faculty of the Graduate School \\ of Cornell University \\ in Partial Fulfillment of the Requirements for the Degree of \\ Master of Science
}

by

Christopher Axtell Kanter

February 2010 
(C) 2010 Christopher Axtell Kanter 


\begin{abstract}
Production labeling is a common approach for differentiating otherwise similar products in the marketplace. While these labels may convey positive messages to consumers about the new product, they may simultaneously stigmatize the conventionally-produced product by highlighting perceived problems. The net economic result for producers can be negative since consumers may decrease their willingness to pay for the conventional product that dominates the market, while the new product has a relatively small market share. This research identifies this stigma effect in the case of milk, where the introduction of rBST-Free and organic milk reduces consumers' willingness to purchase conventional milk.

In this thesis, the question of whether production labeling is driving consumer's bias against conventional milk is investigated in an experimental setting by eliciting the willingness to pay in a sample of Cornell University staff and graduate students for milk produced via different production methods and of varying fat contents. Through altering the order in which participants bid for the different types of milk and analyzing the resulting data using a two-limit random-effect Tobit model with instrumental variables, we find that consumers are indeed willing to pay a premium for rBST-Free and organic milk despite a lack of scientific evidence regarding harmful effects of rBST on human health.

The results illustrate that, by varying the order in which experiment participants were allowed to taste and learn information about milk produced using different techniques, we are able to demonstrate that participants were willing to pay less for milk produced using rBST after being exposed to rBST-Free and organic milk, and likewise, willing to pay more for rBST-Free and organic milk after being exposed to milk produced using rBST. In a situation where milk produced using all three
\end{abstract}


techniques is available, the end result is a higher price charged for rBST-Free and organic milk and decreased revenue for farmers and distributors who deal in milk produced using hormones. The implications of the experiment are fairly straightforward - production labeling can indeed be a strong influence on consumer's perception of a good, and producers of conventional goods in markets where alternative products are being introduced need to be aware of the potential impact of the availability of the new product on the demand for the conventional product. 


\section{BIOGRAPHICAL SKETCH}

The author was born February 12, 1981 in Plattsburgh, New York. His early years were spent in White Plains, New York. In 1994, he moved to Ithaca, New York, where he graduated from Ithaca High School in 1999, and subsequently graduated with a degree in economics from Cornell University in 2003.

After a hiatus from academics, he found himself back at Cornell University once again in 2005, this time studying dairy economics under Professor Harry M. Kaiser. The author is currently a $\mathrm{PhD}$ candidate at the University of Wisconsin, Madison where he is focusing on agricultural production in the Agricultural and Applied Economics department. 


\section{ACKNOWLEDGEMENTS}

I am extremely grateful to Harry Kaiser. His experience and guidance has been an invaluable resource. Without his support I could not have conducted any experiments, completed this thesis, or continued my education in Wisconsin. Thank you so much Harry.

I would also like to thank Kent Messer. Kent's knowledge of experimental economics was fundamental to conducting our experiments, and his input and editing was vital to improving the quality of this paper.

Many thanks to William Schulze, whose advice in designing the experiment was especially helpful in determining the direction of our research.

Special thanks to Anita Vogel. Anita was a life saver on multiple occasions when we ran into problems running the experiments, as well as providing most excellent company during the long process of writing this paper.

This work was possible due to the support of the New York State Milk Promotion Board, the National Institute for Commodity Promotion Research and Evaluation, and the National Science Foundation. 
Biographical Sketch...........................................................................................ii

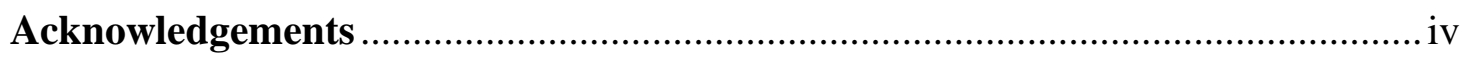

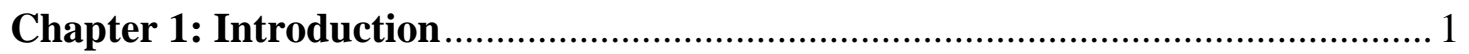

Chapter 2: Literature Review ............................................................................... 4

2.1 Stigma and its Influence on Consumer's Perception

of rBST-Free Milk ........................................................................................... 6

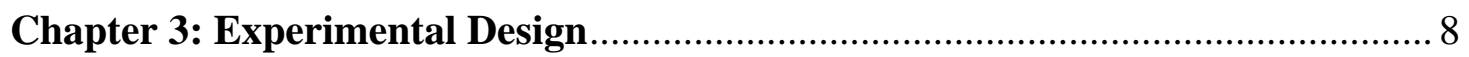

3.1 Experiment Parts A and B: Understanding the Incentive

Compatibility of the BDM Mechanism .............................................................. 9

3.2 Experiment Part C: WTP for Milk ……………………………………... 12

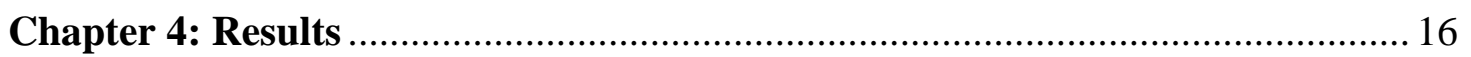

4.1 Difference in WTP Between rBST-Free and

Conventional Milk.......................................................................................... 22

4.2 Difference in WTP Between Organic and Conventional Milk .................... 25

4.3 Difference in WTP Between Organic and rBST-Free Milk ......................... 26

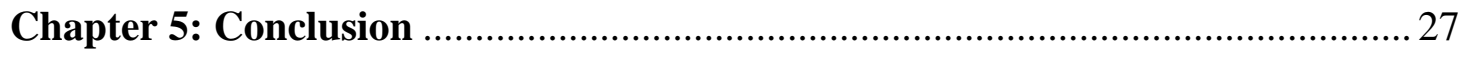

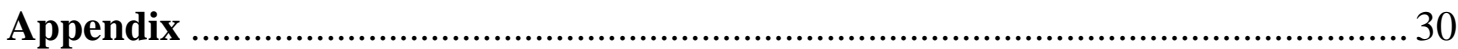

Appendix 1: Experiment Instructions............................................................... 30

Appendix 2: Tasting Template ………………………………....................... 37

Appendix 3: Nutrition Information ................................................................ 38

Appendix 4: Post-Experiment Questionnaire ...................................................... 39

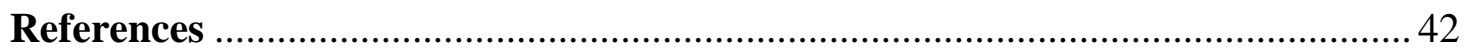




\section{LIST OF FIGURES}

Figure 1: Percentage of subjects willing to pay at a particular price

by the order the milks were presented......................................18 


\section{LIST OF TABLES}

Table 1: Experiment design ..........................................................................

Table 2: WTP and tasting values for milk by fat type and production method ............ 16

Table 3: Average WTP for milk by fat type, production method, and order of tasting ............................................................................... 17

Table 4: Average tasting values for milk by fat type, production method,

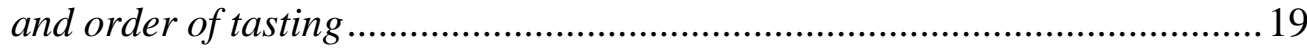

Table 5: Two-limit, random-effect tobit model of differences between WTP ............... 23 


\section{Chapter 1}

\section{Introduction}

Ideally, the labeling of products based on the production methods used should improve consumers' welfare by offering more choices, while at the same time allow producers to differentiate their products and potentially secure additional profits from consumers who are willing to pay (WTP) more for a commodity produced with "preferable" methods. However, labeling to promote the benefits of one technique may also cast the conventional commodity in a negative light. For example, some dairy industry officials are troubled by the labeling of some milk as free of recombinant bovine somatotropin (rBST), which is a synthetically produced version of the naturally occurring hormone bovine somatotropin (bST). Dairy farmers use rBST to boost the milk yields of their dairy cows. Some industry officials believe that labeling some milk products as "hormone free" will stigmatize conventionally produced milk resulting in a reduction in conventional milk or perhaps total fluid milk consumption. ${ }^{1}$ In fact, several states have considered or are considering bans on milk labels that include phrases such as "hormone free" or "contains no artificial hormones" because of the potential stigma effect (Martin 2007).

In ex ante studies of the impact of rBST on consumers' milk purchasing behavior, several factors were found that reduced the demand for milk produced by cows treated with rBST, including the amount of information about rBST that consumers possessed, the quantity of milk they consumed, and how much they were concerned with the level of milk prices (Kaiser, Scherer, and Barbano 1992). This

\footnotetext{
${ }^{1}$ In this article, conventional milk refers to the majority of milk sold in the marketplace, which is unlabeled and may or may not have been produced with rBST. All organic milk and rbST-Free milk comes from farmers that pledge not to administer rbST to their cows
} 
study confirms that, despite assurances from the Food and Drug Administration with respect to the safety of rBST for human consumption, consumers are not convinced that the use of rBST in the general fluid milk supply is in their best interests.

The question of the desirability of rBST for consumers has become even more relevant as large fluid milk processors and retailers, including Wal-Mart, Kroger, Dean Foods, and Starbucks have begun requiring suppliers to cease the use of rBST on their dairy herds. Whether this decision was made with the interests of consumers in mind, or for some other reason, remains unclear. What is clear, however, is consumers are moving away from purchasing conventionally produced milk and towards alternative products that are viewed as safer and more attractive, mainly organic milk and rBST-free milk.

A shift in consumers' preferences away from conventional milk, which may or may not contain rBST, towards rBST-free alternatives is likely to have a significant impact on fluid milk producers. Estimates of rBST adoption rates in the United States vary significantly-from 15\% in Wisconsin herds to as high as 44\% in New York and Texas herds (Barham et al. 2004). According to Monsanto, the largest producer of rBST, $17 \%$ of dairy farmers nationwide used rBST to some degree on their herds and their herds accounted for 33\% of the total number of dairy cows in the U.S. If fluid milk retailers and processors continue to push farmers to stop using rBST on their herds, there will likely be significant costs to the farmers as they transition back to dairy production techniques that do not utilize rBST (Forbes 2008).

In this research, the potential bias of consumers towards conventional milk is examined in the context of stigma, a psychological phenomenon in which an object becomes viewed in a negative manner even when no actual problem or health risk has been identified. The problem is addressed using experimental economics and eliciting WTP for fluid milk produced via differing production methods and varying fat 
contents from adult subjects. Through altering the order in which participants bid for the different types of milk, we find that consumers are willing to pay a premium for organic and/or rBST-free milk despite a lack of scientific evidence regarding harmful effects of conventional milk on human health, and hence it is likely that the trend towards rBST-free milk products is being driven by consumer preferences. 


\section{Chapter 2}

\section{Literature Review}

Early research involving rBST was mainly concerned with how milk production would increase due to rBST adoption and the resulting implications for dairy policy (see, for example, Fallert et al. (1987); McGuckin and Ghosh (1989); and Tauer and Kaiser (1991)). While the supply-side effects of the introduction of rBST into dairy herds were well documented, the effects of introducing an unfamiliar biotechnology into a familiar good, were less well known. A limited number of studies were done to gauge how consumers would react to the presence of rBST in their milk. In a survey of consumers in New York and Virginia, 33\% and $20 \%$ of consumers, respectively, were concerned about the safety of rBST in their milk, and only $30 \%$ and $35 \%$, respectively, believed that milk supplemented with rBST was safe to drink (McGuirk and Kaiser 1991). Additionally, 85\% of the respondents in both states believed that milk containing rBST should be labeled as such, the implication being that they were not fully convinced of the safety of rBST and would like the option of avoiding milk containing it if they so chose. Another study of consumer opinions regarding rBST found that, even taking into account reduced prices from rBST-induced milk production expansion, there would likely be a $1.6 \%$ decrease in milk consumption after the introduction of rBST (Kaiser, Scherer, and Barbano 1992).

The introduction of organic milk is the closest parallel to that of rBST-free milk. While there has been much economic research on organic milk, little has been done on its potential stigma effect on conventional milk. However, there has been some research regarding premiums that consumers are willing to pay for organic milk. Using scanner data and a hedonic econometric model, Bernard and Mathios (2005) 
found that consumers were willing to pay premiums for both organic ( $\$ 0.73$ per gallon) and rBST-free ( $\$ 0.26$ per gallon) milk. The higher price premium for organic milk implies that consumers are willing to pay more for the additional attributes that correspond with organic production. Bernard and Bernard (in press) used experimental price auctions to decompose consumers' WTP for various attributes of organic milk, with an emphasis on the rBST-free and the no antibiotic characteristics. They found that consumers place a significant value on both the rBST-free and the no antibiotics attributes of organic milk. Dhar and Foltz (2005) used supermarket scanner data and a quadratic almost ideal demand systems model to examine the value consumers place on having organic and rBST-free milk in the market place in addition to conventional milk. The authors found substantial benefits to consumers ( $\$ 2.53$ billion) in terms of "competitive" and "variety" effects of having these two products in the market. Based on previous research, therefore, it appears that consumers: (1) prefer having a market that offers choice among conventional, organic, and rBST-free milk, and (2) are willing to pay significant premiums for organic milk, and somewhat smaller premiums for rBST-free milk compared with conventional milk. Consumers' reluctance to embrace rBST as a beneficial technology, as well as the presence of conflicting information regarding the safety of rBST in milk, also bears many similarities to consumers' reactions to the use of genetically modified organisms (GMOs) and other biotechnology in food production (e.g., Noussair, Robin, and Ruffieux 2004; and Lusk, Feldkamp, and Schroder 2004). 


\subsection{Stigma and its Influence on Consumer's Perception of rBST-Free Milk}

It seems that consumers' biases against GMO and rBST share many attributes. The question is why the bias against rBST persists. There is a plethora of information available regarding the safety of rBST and much of it is conflicting. A study of decision-making based on divergent risk information found that decision makers will put more weight on high-risk information than on low-risk information (Viscusi 1997). Another study by Fox, Hayes, and Shogren (2002) on consumers’ reactions to food irradiation came to a similar conclusion-- consumers' WTP for irradiated pork decreased more after exposure to negative information than it increased from exposure to positive information regarding the pork. Additionally, it seems that consumers are not adept at assessing food risks. In an experimental study of consumers' WTP for increased food safety, participants were likely to rely more on personal experience than scientific information when determining their values for avoiding illness (Hayes et al. 1995). This could very well be occurring in the case of rBST. With the ease of acquiring information from the internet, it can be difficult for potential milk consumers to separate reliable information about rBST and human health risks from less reliable sources, especially since Canada, Japan, and a number of countries in Europe currently ban the use of rBST entirely. In a situation such as this, where there is conflicting risk information, consumers may put more weight on the high-risk information (or existing personal beliefs) than on the more reliable low-risk information and adjust their purchasing behavior accordingly.

A topic related to the emphasis on high-risk information is the concept of stigma. Stigma can be thought of as "a negative feature that typically pervades and dominates an otherwise acceptable entity” (Rozin 2004). Stigma is passed on via 
direct contact with a contaminated object in a phenomenon known as contagion (Rozin, Millman, and Nemeroff 1986). Another key element of stigma, at least in Western societies, is that people tend to describe their feelings of revulsion for a stigmatized object in terms of how it impacts their health (as opposed to an object possessing some innate evil characteristic). The effects of stigma have been observed in a variety of economic situations such as the large decrease in home values near some toxic waste sites where the actual health risk posed by these sites in many cases has been relatively small and therefore objective risk alone cannot explain the consumer response (Messer et al. 2006; Dale et al. 1999; Adams and Cantor 2001; Guntermann 1995). Other examples of stigmatized products include cyanide in Tylenol bottles, exploding gas tanks that plagued the Ford Pinto, Firestone tire failures on the Ford Explorer, and mad cow disease with beef.

Regarding the possible stigmatization of conventional milk by organic and rBST-free milk, the properties of contagion and medicalization of risk are especially salient. Milk is considered a healthy, desirable food to consume until the milk undergoes contact with rBST via contagion, despite the lack of substantial chemical change in the milk. People who see the addition of rBST to cows producing milk as a negative action tend to cite possible negative health consequences to humans and cows as justification for their views. Both of these properties play into the possible role of production labeling in stigmatizing conventionally produced milk. By distinguishing between conventionally produced and rBST-free milk through the use of labeling, milk retailers can potentially tap into consumers' fears regarding the safety of conventionally produced milk in order to charge higher prices for rBST-free milk. 


\section{Chapter 3}

\section{Experimental Design}

In order to determine whether the presence of rBST stigmatizes milk to consumers, a three-part experiment was designed (see Table 1). Part A consisted of rounds designed to familiarize participants with the Becker-DeGroot-Marschak (BDM) (1964) bidding mechanism, where induced "cash values” were used. Advantages of the BDM mechanism for private goods include its incentive compatibility in an expected utility framework and demand revealing properties, making it ideal for this experiment. $^{2}$ Part B also used the BDM mechanism and had subjects submit bids to purchase a pencil. Finally, Part C used the BDM mechanism to elicit WTP values for milk produced using three production techniques (conventional, rBST-free, and organic) and three fat contents ( $0 \%$ skim, $1 \%$ lowfat, and 3.25\% whole). Experiment subjects were recruited via e-mail announcements to graduate student and staff e-mail list servers, as well as through PawprintFlash, an online publication containing articles, information, and announcements for Cornell University employees. Fifteen experiment sessions were conducted. Each session lasted approximately one hour and the average earnings were $\$ 15$.

For each part of the experiment, participants received written instructions ${ }^{3}$ with an oral explanation and were provided a chance to ask questions. Subjects were seated

\footnotetext{
${ }^{2}$ As pointed out by Karni and Safra (1987) and Horowitz (2006), the BDM in a private good context where the price is unknown may not be incentive compatible in cases outside of the expected utility model. Their argument is also true with the alternative WTP elicitation mechanisms commonly used in experimental settings, such as the Vickrey auction and nth-price auctions. The foundation of this research is based on the assumption of expected utility and the numerous experimental studies that have demonstrated the demand revealing characteristics of the BDM in induced value settings (i.e., Irwin et al. 1998; Messer et al. 2008).

${ }^{3}$ See Appendix 1 to view the experiment instructions.
} 
Table 1: Experiment design

\begin{tabular}{|c|c|c|c|c|c|c|}
\hline Part & Item for Sale & $\begin{array}{c}\text { Initial } \\
\text { Balance }\end{array}$ & $\begin{array}{c}\text { Range } \\
\text { of } \\
\text { Costs }\end{array}$ & $\begin{array}{c}\text { Bids per } \\
\text { Round }\end{array}$ & $\begin{array}{c}\text { Cash Payoff } \\
\text { Rounds }\end{array}$ & $\begin{array}{c}\text { Exchange } \\
\text { Rate }\end{array}$ \\
\hline A & $\begin{array}{c}\text { Cash Values: } \\
\$ 1, \$ 2.50, \$ 4\end{array}$ & $\$ 5.00$ & $\begin{array}{c}\$ 0.00- \\
\$ 4.99\end{array}$ & 1 & 5 & $2: 1$ \\
\hline B & Pencil & $\$ 0.50$ & $\begin{array}{c}\$ 0.00- \\
\$ 0.49\end{array}$ & 1 & 1 & $1: 1$ \\
\hline C & $\begin{array}{c}\text { Quart of Milk } \\
\text { Fat Types: } 1 \%, 3.25 \% \\
\text { Production Type: } \\
\text { Conventional, } r \text { BST- } \\
\text { free, Organic }\end{array}$ & $\$ 5.00$ & $\begin{array}{c}\$ 0.00- \\
\$ 4.99\end{array}$ & 9 & 1 & $1: 1$ \\
\hline
\end{tabular}

randomly at computers that were equipped with privacy shields, and no communication was permitted between subjects. Experiment data was collected using Excel spreadsheets programmed in Visual Basic. At the completion of the experiment, participants were asked to fill out a questionnaire regarding their milk purchasing behavior and knowledge, their attitudes towards risk, and general demographic information. ${ }^{4}$

\subsection{Experiment Parts A and B: Understanding the Incentive Compatibility of the BDM Mechanism}

Part A consisted of five rounds. At the start of each round, $t$, participants were provided with a $\$ 5$ initial balance, $Y_{t}$, and were presented with a "cash value", $V_{t}$, of

\footnotetext{
${ }^{4}$ See Appendix 2 to view the post-experiment questionnaire
} 
$\$ 1$, $\$ 2.50$, or $\$ 4$ (see Table 1). Participants were then asked to record the highest amount that they would be willing to pay to receive that cash value-we refer to this amount as their "bid," $B_{i t}$. Once all participants recorded their bids, a price, $C_{t}$, was drawn from a random-number table containing values from \$0 to \$4.99 and announced to all the subjects.

As described by Irwin et al. (1998), utility-maximizing subjects in this mechanism submit a bid given an initial income $Y^{0}$ that maximizes:

(1) $\quad E U=\int_{0}^{B} p(C) U\left(Y^{0}+E+V-C\right) d R+\int_{B}^{E} p(C) U\left(Y^{0}+E\right) d R$

Examination of the left side of equation (1) shows that it is not in the best interest of a participant to bid less than her actual WTP. In the event that the randomly drawn price falls between her actual WTP and her stated WTP, the participant loses the opportunity to earn a larger profit. The logic behind not overstating WTP is shown in the right side of equation (1). Participants would not want to submit bids that are greater than their actual WTP_-if a participant bids higher than her actual WTP and the randomly selected price is between her actual WTP and her stated WTP, she could potentially end up paying more than her value for an object. The derivative of equation (1) with respect to $B$ leads to:

(2) $\frac{d E U}{d B}=p(B)\left[U\left(Y^{0}+E+V-B\right)-U\left(Y^{0}+E\right)\right]=0$

Since the probability of the bid being equal to the price is $(p(B)>0$, participants who are maximizing their utilities will submit bids equal to value $(B=V)$, demonstrating the incentive compatibility of the mechanism.

Each round produced two possible outcomes for the participants that depended on their bids and the random price. If the participant's bid was greater than or equal to the random price $\left(B_{i t} \geq P_{t}\right)$, the participant purchased the cash value at the randomly 
selected price, yielding a payoff of $Y_{t}+\pi_{t}-P_{t}$. However, if the participant's bid was less than the price $\left(B_{i t}<P_{t}\right)$, then the participant retained only the initial balance, $Y_{t}$.

The primary objective of Part A was to give subjects an opportunity to learn how the BDM mechanism operates. To this end, the procedures followed those of Noussair, Robin, and Ruffieux (2004); participants were informed that the best strategy for each round was to place a bid equal to the cash value $\left(B_{t}=\pi_{t}\right)$ since that would result in the participants receiving the greatest possible payoff for each round regardless of the price. To reinforce this message, at the conclusion of each round of Part A, participants were given the chance to view the bids from all of the subjects in the round, the random price, and the payoff outcomes. The bids were displayed on a screen at the front of the laboratory, listed in order from the lowest bid to the highest without identifying which participants had submitted each bid. The subjects could thus see how closely their strategies for bidding matched the optimal strategy that yielded the greatest possible earnings.

Part B of the experiment served as a transition from Part A to Part C. In Part A, participants were asked to bid on an exogenously selected cash value, which for some can be a difficult concept to understand. Part B provided a bridge between Part A and Part C so that participants could accustom themselves to implementing the BDM mechanism with a real-world object for which each person had a unique, endogenously selected value. In Part B, participants were asked to bid on a Ticonderoga-brand pencil. Part B consisted of a single round of bidding, participants were given an initial balance of $\$ 0.50$, and they were asked to bid between $\$ 0$ and $\$ 0.50$ for a pencil. Once all of the bids had been submitted, a price between $\$ 0$ and $\$ 0.49$ was determined using a new random-number table. As in Part A, if the bid was equal to or greater than the price, the participant received the pencil and its price was subtracted from her initial balance. If the bid was lower than the price, the 
participant did not receive a pencil but retained the entire initial balance of $\$ 0.50$. At the end of the round, pencils were handed out to participants whose bids were successful.

\subsection{Experiment Part C: WTP for Milk}

For Part $\mathrm{C}$ of the experiment, participants were given an initial balance of $\$ 5$ and asked to submit bids ranging from $\$ 0$ to $\$ 5$ for nine different food items that would be presented sequentially. ${ }^{5}$ Participants were told that, after submitting bids for each of the nine food items, they would learn which item and corresponding bids would be used to determine the final payout. This selection would be done randomly so subjects were advised to submit bids for each food item as if it would be the one used to determine cash earnings. This type of experiment is commonly referred to as a withinsubject design as the same subject is asked multiple questions. An advantage of within-subject designs is that they allow for direct comparisons of how the a person views different types of products and information while also naturally controlling for a variety of individual-specific observable and unobservable elements, such as confusion about the operation of the bidding mechanism or experiment procedures. For instance, if a subject consistently submits bids that exceed her true WTP due to confusion about the BDM mechanism, a within-subject design helps control the

\footnotetext{
${ }^{5}$ Unlike other experiments on food preferences, this design did not endow participants with a base product (such as conventional milk) and then assess their WTP for upgrading to another product, such as rBST-free milk. The endow-and-upgrade design was made popular by Shogren et al. (1994) but has been shown to affect WTP results in some experimental settings (Corrigan and Rousu 2006; Lusk, Feldkamp, and Schroeder 2004). However, in the case of their review of endowment biases in BDM auctions, Lusk, Feldkamp, and Schroeder (2004) pointed out that providing an endowment does not significantly affect bids in the BDM mechanism (p. 404). In this design, the "upgrade" options were not defined, especially the differences in fat type where a consumer makes a trade-off between taste and fat intake preferences, so only a positive WTP for the products was elicited.
} 
influence of this overbidding since it occurs for all of the products the participant considers. By analyzing the data with a mixed-model two-limit Tobit that clusters across the individual (as described later), this research further controls for errors resulting from receiving multiple observations from the same participant.

The nine choices of milk in Part C were presented in three flights based on production type: conventional, rBST-free, and organic (see Table 1). For each flight of milk, participants were given a three-column taste-testing template, along with three five-ounce tasting cups, each filled with the same type of milk but varying by fat content $-0 \%$ skim, $1 \%$ lowfat, and 3.25\% whole. Participants were asked to taste each cup of milk and afterwards to answer two questions regarding the quality and freshness of each sample. ${ }^{6}$ The questions asked, on a scale of one to ten, how closely the taste of the milk matched the subjects’ expectations of fresh, high-quality milk and how well they liked the milk sample overall. The taste-testing questions were based on two hedonic milk studies in which experiment participants were asked to rate their level of "like" for milk, as well as rating the intensity of various milk characteristics (Chapman and Boor 2001; Chapman, Lawless, and Boor 2001). After answering the tasting questions, participants submitted bids representing the highest amount that they would pay for a one-quart carton of this type of milk.

In the context of this research, it is of interest to compare how participants bid on the samples of milk with which they were presented in the experiment to how they would make a milk purchase decision in the real-world context of a grocery store. With the introduction of rBST-free milk in the marketplace, a typical milk consumer's set of choices expanded from eight milk varieties (conventional or organic milk and $0 \%, 1 \%, 2 \%$, or $3.25 \%$ fat) to twelve. Our experiment design focused on recreating, as much as possible, the set of products a milk consumer would consider in making a

\footnotetext{
${ }^{6}$ See Appendix 2 to view the taste-testing template.
} 
purchase decision-in this case, nine milk varieties (conventional, rBST-free, or organic milk and $0 \%, 1 \%$, and 3.25\% fat)—and then asked the subjects to bid on milk produced using a given method in isolation, without considering their WTP for milk produced using the other two methods. While the ideal experimental design would be a perfect replication of the real-world milk purchase decision (Louviere 2006), this experimental design offers several advantages. First, the experiment is aided by the familiarity of the purchase decision since the adult participants in this study had made milk purchases repeatedly over many years and are accustomed to considering the purchase of milk at different prices (such as price differences commonly observed for different container sizes or whether the milk is purchased at a grocery store, shoppers club, or convenience store) and with different characteristics (such as organic/conventional production or flavored milk).

Furthermore, to answer the question posed in this study, use of the BDM mechanism is superior to a dichotomous yes/no choice on a posted price (the setting most commonly found in marketplaces) because the BDM mechanism provides specific point estimates for a consumers' WTP for different types of milk, something that would be very costly to do with dichotomous choice as the posted prices would have to be varied over a large range of possibilities, requiring a much larger sample size. Finally, these objective bids, along with questionnaire data and data regarding the order in which the different types of milk were presented, can be combined to analyze how the introduction of rBST-free milk into the market impacted consumers' WTP for conventional milk.

To mimic the information provided in a grocery store setting, subjects were given handouts containing nutrition and production information for each flight of milk. Importantly, the nutrition information differed only by fat type and not by 
production technique. $^{7}$ The information handout for rBST-free milk included a statement that the milk "does not contain artificial growth hormones" and the handout for organic milk included a statement that the milk was "produced without the use of antibiotics, synthetic growth hormones, or pesticides.” The wording for both statements came directly from the labels on the cartons of the original milks. The information sheet for conventional milk was labeled as "conventional milk" and did not make any claims regarding the production process. In the oral protocols, participants were informed that conventional milk was the type of milk most commonly available in grocery and convenience stores. To avoid any packaging or branding effect, all nine milks were served in clear pitchers and subjects did not see the brands of milk used in the experiment.

Once all nine bids had been placed and the milk type selected, a price was drawn at random and the quarts of milk were distributed to those whose bids were successful.

\footnotetext{
${ }^{7}$ See Appendix 3 to view the nutrition information handout.
} 


\section{Chapter 4}

\section{Results}

The experimental results from 148 adult subjects support the existence of a stigma effect from both organic and rBST-free milk on conventional milk. However, when looking at average WTP for milk of a given fat type, the stigma effect - especially the one from the introduction of milk labeled rBST-free - is initially difficult to detect. For example, as seen in Table 2a, participants' average WTP was $\$ 1.03$ for skim milk produced conventionally, $\$ 1.06$ for skim milk produced without rBST, and $\$ 1.40$ for skim milk produced using organic practices; the average tasting scores for these skim milks were 4.87, 4.87, and 6.18, respectively. The stigma effect becomes apparent when the average WTP values are separated by the order in which the milks were presented. The impact of the order of presentation is shown in Figure 1. Most notable is the decrease in overall WTP for conventional milk from when it was presented first to when it was presented last (Figure 1a). When conventional milk was the first

Table 2: WTP and tasting values for milk by fat type and production method

a) $0 \%$ and $1 \%$ Milk

\begin{tabular}{|c|cc|cc|}
\hline & \multicolumn{2}{|c|}{ 0\% Milk } & \multicolumn{2}{c|}{ 1\% Milk } \\
\hline & WTP & $\begin{array}{c}\text { Difference from } \\
\text { Conventional }\end{array}$ & WTP & $\begin{array}{c}\text { Difference from } \\
\text { Conventional }\end{array}$ \\
\hline $\begin{array}{c}\text { Conventional } \\
\text { rBST-free }\end{array}$ & $\$ 1.03$ & - & $\$ 1.11$ & - \\
Organic & $\$ 1.06$ & $+\$ 0.03$ & $\$ 1.14$ & $+\$ 0.03$ \\
& Tasting & Difference from & Tasting & Difference from \\
& Score & Conventional & Score & Conventional \\
\hline Conventional & 4.87 & - & 5.76 & - \\
rBST-free & 4.87 & 0.00 & 5.56 & -0.20 \\
Organic & 6.18 & +1.31 & 6.75 & +0.99 \\
\hline
\end{tabular}




\section{Table 2 (Continued)}

b) $3.25 \%$ Milk and Overall Averages

\begin{tabular}{|c|cc|cc|}
\hline & \multicolumn{2}{|c|}{ 3.25\% Milk } & \multicolumn{2}{c|}{ Overall } \\
\hline & \multicolumn{3}{|c|}{$\begin{array}{c}\text { Difference from } \\
\text { Conventional }\end{array}$} & \multicolumn{2}{c|}{ WTP } & $\begin{array}{c}\text { Difference from } \\
\text { Conventional }\end{array}$ \\
\hline Conventional & $\$ 1.04$ & - & $\$ 1.06$ & - \\
rBST-free & $\$ 1.02$ & $-\$ 0.02$ & $\$ 1.08$ & $+\$ 0.02$ \\
Organic & $\$ 1.23$ & $+\$ 0.19$ & $\$ 1.35$ & $+\$ 0.29$ \\
\hline & Tasting & Difference from & Tasting & Difference from \\
& Score & Conventional & Score & Conventional \\
\hline Conventional & 5.60 & - & 5.41 & - \\
rBST-free & 5.45 & -0.15 & 5.30 & -0.11 \\
Organic & 6.26 & +0.66 & 6.40 & +0.99 \\
\hline
\end{tabular}

product presented, the average WTP offer was $\$ 1.28$ (Table 3). However, when conventional milk was presented last (the third of three flights), the subjects were aware of the complete set of products, had the chance to taste all of them, and, much like in a grocery store, were presented with a wide variety of milk choices. In this case, average WTP values for conventional milk fell to $\$ 0.61$ (a decline of 52.3\%). On

Table 3: Average WTP for milk by fat type, production method, and order of tasting

\section{Tasted First}

\begin{tabular}{|c|c|c|c|c|c|}
\hline & $\begin{array}{c}\text { WTP } \\
\text { Conventional } \\
\end{array}$ & $\begin{array}{l}\text { WTP } \\
\text { rBST- } \\
\text { free } \\
\end{array}$ & $\begin{array}{c}\text { Difference } \\
\text { from } \\
\text { Conventional }\end{array}$ & $\begin{array}{c}\text { WTP } \\
\text { Organic }\end{array}$ & $\begin{array}{c}\text { Difference } \\
\text { from } \\
\text { Conventional }\end{array}$ \\
\hline 0\% Skim & $\$ 1.23$ & $\$ 1.03$ & $-\$ 0.20$ & $\$ 1.53$ & $+\$ 0.20$ \\
\hline 1\% Lowfat & $\$ 1.37$ & $\$ 1.16$ & $-\$ 0.21$ & $\$ 1.39$ & $+\$ 0.02$ \\
\hline $3.25 \%$ Whole & $\$ 1.52$ & $\$ 1.24$ & $-\$ 0.28$ & $\$ 1.19$ & $-\$ 0.33$ \\
\hline All Fat Types & $\$ 1.28$ & $\$ 1.05$ & $-\$ 0.23$ & $\$ 1.37$ & $+\$ 0.09$ \\
\hline \multicolumn{6}{|c|}{ Tasted Last } \\
\hline & $\begin{array}{c}\text { WTP } \\
\text { Conventional }\end{array}$ & $\begin{array}{l}\text { WTP } \\
\text { rBST- } \\
\text { free } \\
\end{array}$ & $\begin{array}{c}\text { Difference } \\
\text { from } \\
\text { Conventional }\end{array}$ & $\begin{array}{c}\text { WTP } \\
\text { Organic }\end{array}$ & $\begin{array}{c}\text { Difference } \\
\text { from } \\
\text { Conventional }\end{array}$ \\
\hline 0\% Skim & $\$ 0.55$ & $\$ 1.14$ & $+\$ 0.59$ & $\$ 1.32$ & $+\$ 0.77$ \\
\hline 1\% Lowfat & $\$ 0.64$ & $\$ 1.22$ & $+\$ 0.58$ & $\$ 1.41$ & $+\$ 0.77$ \\
\hline $3.25 \%$ Whole & $\$ 0.63$ & $\$ 1.09$ & $+\$ 0.46$ & $\$ 1.34$ & $+\$ 0.71$ \\
\hline All Fat Types & $\$ 0.61$ & $\$ 1.15$ & $+\$ 0.54$ & $\$ 1.36$ & $+\$ 0.75$ \\
\hline
\end{tabular}


a) Conventional Milk

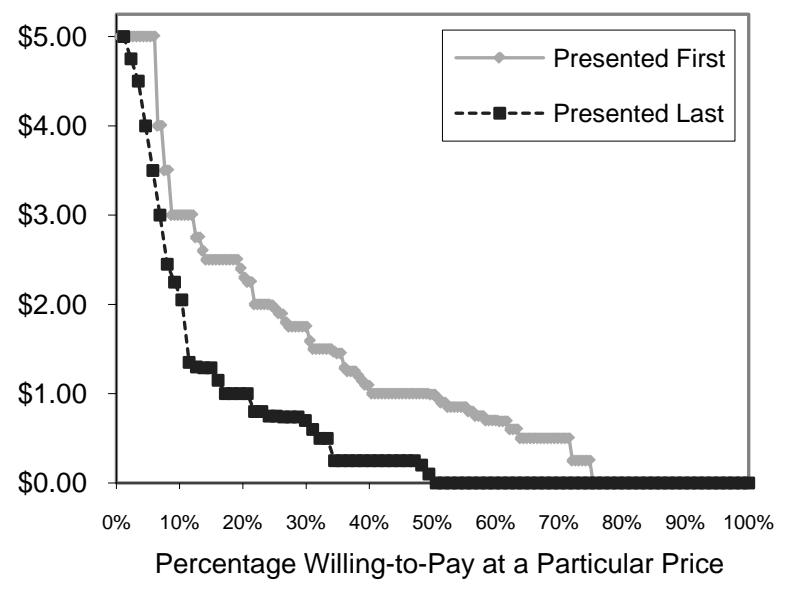

b) rBST-Free Milk

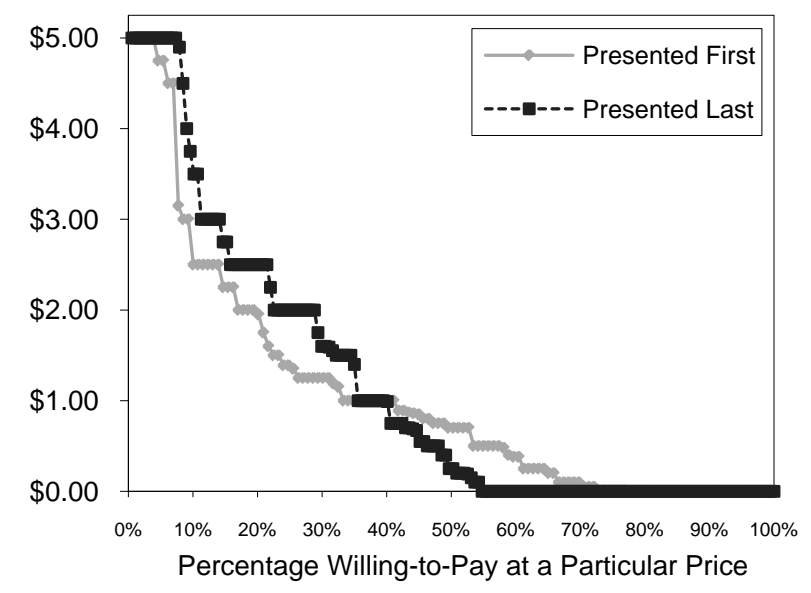

c) Organic Milk

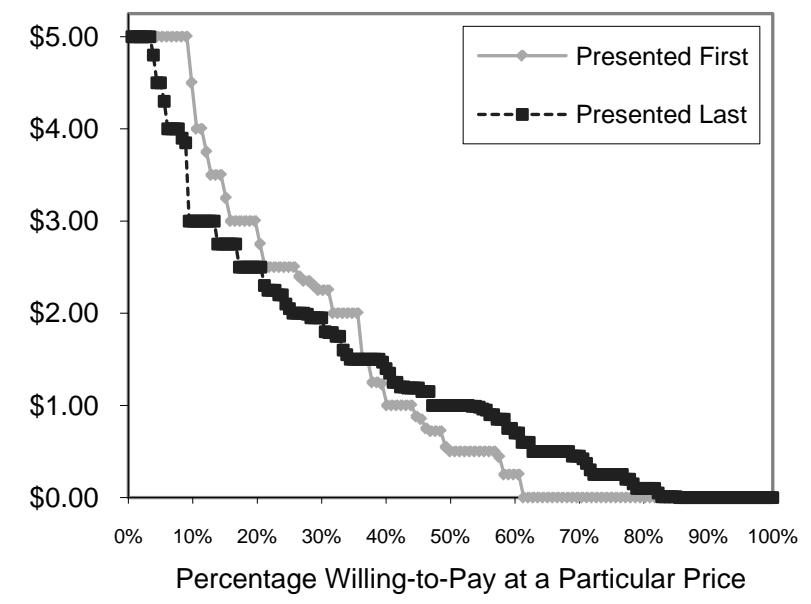

Figure 1: Percentage of subjects willing to pay at a particular price, by the order the milks were presented 
the other hand, the trend for rBST-free milk is different as the values generally increased (Figure 1b). When rBST-free milk was presented first, the mean WTP was \$1.05; when the same milk was presented last, the mean WTP increased by $9.5 \%$ to \$1.15. Organic milk saw essentially no change in WTP due to order, as mean WTP was $\$ 1.37$ when presented first and $\$ 1.36$ when presented last.

While some of the decline in WTP for conventional milk may have been anticipated since the average tasting value for conventional milk dropped $15.9 \%$ from 5.92 when presented first to 4.98 when presented last (Table 4), the decrease in perceived taste does not explain all of the decline. For example, rBST-free milk saw an even more dramatic decrease in its tasting value due to order-from 6.31 when presented first to 4.86 when presented last (a decline of 23.0\%)—even though the WTP increased by $9.5 \%^{8}$

Table 4: Average tasting values for milk by fat type, production method, and order of tasting

\section{Tasted First}

\begin{tabular}{c|ccccc}
\hline & \multicolumn{3}{|c}{$\begin{array}{c}\text { Difference } \\
\text { from } \\
\text { CosT- } \\
\text { free }\end{array}$} & $\begin{array}{c}\text { Conventional } \\
\text { Conventional }\end{array}$ & $\begin{array}{c}\text { Oifference } \\
\text { from } \\
\text { Conventional }\end{array}$ \\
\hline 0\% Skim & 5.47 & 6.00 & +0.53 & 6.45 & +0.98 \\
1\% Lowfat & 6.22 & 6.67 & +0.45 & 6.57 & +0.35 \\
3.25\% Whole & 6.07 & 6.26 & +0.19 & 5.62 & -0.45 \\
All Fat Types & $\mathbf{5 . 9 2}$ & $\mathbf{6 . 3 1}$ & $\mathbf{+ 0 . 3 9}$ & $\mathbf{6 . 2 1}$ & $\mathbf{+ 0 . 2 9}$ \\
\hline
\end{tabular}

Tasted Last

\begin{tabular}{c|ccccc}
\hline & \multicolumn{3}{|c}{$\begin{array}{c}\text { Difference } \\
\text { from } \\
\text { rBST- } \\
\text { free }\end{array}$} & $\begin{array}{c}\text { Conventional } \\
\text { Organic }\end{array}$ & $\begin{array}{c}\text { Difference } \\
\text { Conventional } \\
\text { Conventional }\end{array}$ \\
\hline 0\% Skim & 4.43 & 4.19 & -0.24 & 6.25 & +1.82 \\
1\% Lowfat & 5.07 & 5.22 & +0.15 & 6.93 & +1.86 \\
3.25\% Whole & 5.43 & 5.16 & $-\$ 0.27$ & 6.45 & +1.02 \\
All Fat Types & $\mathbf{4 . 9 8}$ & $\mathbf{4 . 8 6}$ & $\mathbf{- 0 . 1 0}$ & $\mathbf{6 . 5 4}$ & $\mathbf{+ 1 . 5 6}$ \\
\hline
\end{tabular}

\footnotetext{
${ }^{8}$ Not all of the tasting values declined with the introduction of additional milk products. For instance, the average taste values for organic milk increased from 6.21 when presented first to 6.54 when presented last.
} 
A stigma effect is also potentially present when we pool together the subjects' WTP for milk produced using all three techniques, effectively considering a single demand curve for conventionally produced, rBST-free, and organic milk. The mean WTP for all three milk types when conventional milk was presented first was $\$ 1.22$; the mean WTP when conventional milk was presented third was $\$ 0.90$ (the difference in mean WTP is statistically significant at the $1 \%$ level, $(\mathrm{p}=0.0014))$. This suggests that the introduction of milk labeled as being rBST-free or organic could have a much greater influence than simply reducing WTP for conventional milk—-the availability of rBST-free and organic milk could reduce the demand for all types of milk.

While the descriptive statistics and figures previously discussed are suggestive of a stigma effect, to evaluate formally whether this phenomenon is a result of the order, a detailed analysis of subjects' WTP is necessary. Since participants in the experiments were asked to submit bids for multiple milks with varying fat types and these bids were constrained to between $\$ 0.00$ and $\$ 5.00$, we utilized a two-limit random-effect Tobit model. To evaluate whether there is a stigma effect from milk labeled as rBST-free and organic on conventional milk, the differences in WTP for milks with the same fat content were evaluated in three different models. ${ }^{9}$

The models included dummy variables to indicate the fat content of the milk (FAT1 - 1\% lowfat milk; FAT3 - 3.25\% whole milk), whether the participant was the primary shopper in the household (PRIME_SHOP), whether the participant was aware of the availability of rBST-free (RBST_AVAIL) and organic milk (ORG_AVAIL) prior to the experiment, whether the participant was lactose intolerant (LACT_INT), and the participant's gender ( $M A L E$ ). The participants responded to questions related to the

\footnotetext{
${ }^{9}$ Censored bids (bids of $\$ 0$ or $\$ 5$ ) that did not differ between the milks with different labels were excluded from the analysis, since-given the censored nature of the data - the analysis could not determine whether there was truly a zero difference between the subjects' WTP (or willingness to accept (WTA) in the case of censored bids of \$0) for the milks or whether the change in real WTP/WTA occurred outside the range of observation.
} 
frequency with which they purchased conventional (FREQ_CONV), rBST-free (FREQ_RBST), and organic milk (FREQ_ORG) and how risky they considered milk (MILK_RISK). ${ }^{10}$ Subjects also reported the number of children under ten in the household (CHU10), the highest level of education obtained (EDUC), and income (INCOME). As a control on the participants' understanding of the BDM mechanism, a variable was included to represent their deviations from the final induced-value round during the first part of the experiment $(B D M)$. Since a participant's perceptions of the taste of a milk could have been influenced by the order in which presentation of the milks, a two-stage model was used that included estimated values for the differences in taste values (TASTE_RC, TASTE_OC, and TASTE_OR) as instrumental variables to avoid simultaneous-equation bias. ${ }^{11}$

The average values for some of these variables offer insight into the demographic breakdown of the participants. For example, 83\% identified themselves as the primary shopper for the household and household milk consumption averaged almost 1.5 gallons per week of mainly conventional milk. Awareness of organiclabeled milk in the marketplace was much greater (92\%) than was awareness of milk labeled as rBST-free (just 54\%). The average participant attended some college without earning a degree and had an annual household income of slightly more than $\$ 57,000 ; 27 \%$ of households had children under the age of ten living at home.

Most importantly for our analysis, a dummy variable was included to indicate the order in which the flights of milk were presented. Conventional milk was labeled as $C$, rBST-free milk as $R$, and organic milk as $O$. Thus, the order of presentation was indicated by the order of the letter code. For example, if rBST-free milk was presented

\footnotetext{
${ }^{10}$ The value for the risk-preference variable is the mean of the answers to four questions regarding the participants' attitudes towards the riskiness of pesticides, antibiotics, artificial hormones, and herbicides/fungicides - a higher number indicates a higher level of concern for a given risk factor. ${ }^{11}$ The explanatory variables in the analysis of the difference in taste variables were the same as those used in the general model except that the exact order of the presentation of the milk was also included.
} 
before conventional milk, the dummy variable for the session was $R C$. Likewise, if organic milk was presented before conventional milk, that session was coded as OC. By setting up the models in this manner, we were able to isolate the effect of varying the order of presentation with the order variables $-R C, O C$, and $O R$-representing the size of the stigma effect and the coefficients on the other variables representing the price premium that participants with that particular attribute would pay for the alternative milk, ceteris paribus.

Using these models, we were able to test three different hypotheses regarding how participants' WTP for milk changes as the order in which they taste flights of milk is altered. The null hypothesis in each of the cases asserts that difference in WTP for the milk does not change as the order the flights are tasted changes, while the alternative hypothesis asserts that WTP for milk varies as the order changes.

\subsection{Difference in WTP Between rBST-Free and Conventional Milk}

As seen in column (1) of Table 5, the difference in WTP when rBST-free milk is presented before conventional milk (Model 1) shows that the marginal effect coefficient $^{12}$ for the order dummy variable $R C(0.351)$ is statistically significant $(\mathrm{t}=$ 2.35, $p=0.019)$. Thus, we can reject the hypothesis that order does not affect WTP for rBST-free and conventional milk. The coefficient for $R C$ indicates that participants are willing to pay \$0.35 per quart less for conventional milk after tasting and being exposed to label information regarding rBST-free milk (i.e., rBST-free milk "does not contain any artificial growth hormones”).

\footnotetext{
${ }^{12}$ Marginal effect coefficients deflate the Tobit coefficients so that we may directly examine the marginal effect of increasing a given dependent variable one unit. We cannot make this comparison with the normal Tobit coefficients.
} 
Table 5: Two-limit, random-effect tobit model of differences between WTP

\begin{tabular}{|c|c|c|c|c|c|c|}
\hline \multirow[b]{2}{*}{ Variable } & \multicolumn{2}{|c|}{$\begin{array}{c}\text { (1) rBST-Free - } \\
\text { Conv. }\end{array}$} & \multicolumn{2}{|c|}{ (2) Organic - Conv. } & \multicolumn{2}{|c|}{$\begin{array}{l}\text { (3) Organic - } \\
\text { rBST-Free }\end{array}$} \\
\hline & Coeff. & Std. Error & Coeff. & Std. Error & Coeff. & Std. Error \\
\hline CONSTANT & $-4.850 * *$ & $(-1.033)$ & $-2.448^{*}$ & $(-1.011)$ & 0.406 & $(-1.339)$ \\
\hline$R C$ & $0.351^{*}$ & $(-0.149)$ & & & & \\
\hline$O C$ & & & $0.482 * *$ & $(-0.163)$ & & \\
\hline OR & & & & & 0.024 & $(-0.165)$ \\
\hline TASTE_RC & $0.125^{* *}$ & $(-0.032)$ & & & & \\
\hline TASTE_OC & & & 0.051 & $(-0.062)$ & & \\
\hline TASTE_OR & & & & & 0.009 & $(-0.063)$ \\
\hline FAT1 & 0.024 & $(-0.679)$ & -0.029 & $(-0.084)$ & -0.042 & $(-0.078)$ \\
\hline FAT3 & 0.019 & $(-0.072)$ & -0.112 & $(-0.125)$ & -0.112 & $(-0.096)$ \\
\hline FREQ_CONV & $0.166^{*}$ & $(-0.072)$ & -0.029 & $(-0.079)$ & -0.091 & $(-0.069)$ \\
\hline FREQ_RBST & $0.201 *$ & $(-0.090)$ & 0.129 & $(-0.103)$ & 0.122 & $(-0.110)$ \\
\hline FREQ_ORG & 0.146 & $(-0.077)$ & 0.011 & $(-0.074)$ & -0.076 & $(-0.077)$ \\
\hline PRIME_SHOP & $1.019 * * *$ & $(-0.296)$ & 0.507 & $(-0.305)$ & 0.277 & $(-0.300)$ \\
\hline RBST_AVAIL & 0.256 & $(-0.153)$ & 0.218 & $(-0.191)$ & 0.087 & $(-0.171)$ \\
\hline ORG_AVAIL & -0.334 & $(-0.238)$ & -0.43 & $(-0.247)$ & -0.497 & $(-0.283)$ \\
\hline MILK_RISK & $0.078 * *$ & $(-0.027)$ & $0.096^{* *}$ & $(-0.030)$ & $0.079 * *$ & $(-0.031)$ \\
\hline$M A L E$ & $0.393^{*}$ & $(-0.172)$ & 0.200 & $(-0.183)$ & 0.133 & $(-0.187)$ \\
\hline CHU10 & -0.063 & $(-0.106)$ & -0.068 & $(-0.108)$ & -0.098 & $(-0.111)$ \\
\hline EDUC & $0.083^{*}$ & $(-0.040)$ & 0.058 & $(-0.055)$ & -0.023 & $(-0.045)$ \\
\hline INCOME & 3.01E-06 & $(-1.92 \mathrm{E}-06)$ & $-6.40 \mathrm{E}-07$ & $(-1.97 \mathrm{E}-06)$ & 3.04E-08 & $(-2.43 \mathrm{E}-06)$ \\
\hline$B D M$ & $0.394 *$ & $(-0.161)$ & 0.321 & $(-0.178)$ & 0.157 & $(-0.177)$ \\
\hline LACT_INT & 0.256 & $(-0.199)$ & 0.111 & $(-0.223)$ & -0.212 & $(-0.201)$ \\
\hline Log Likelihood & -271.3 & & -317.0 & & -322.8 & \\
\hline Wald $\chi^{2}$ & 65.74 & & 68.9 & & 25.01 & \\
\hline Prob > chi2 & 0 & & 0 & & 0.095 & \\
\hline \# of Uncensored & 282 & & 294 & & 294 & \\
\hline $\begin{array}{l}\text { \# of Left- } \\
\text { censored }\end{array}$ & 0 & & 0 & & 0 & \\
\hline $\begin{array}{l}\text { \# of Right- } \\
\text { censored }\end{array}$ & 1 & & 3 & & 2 & \\
\hline
\end{tabular}

Note: Significance is indicated by * for the $5 \%$ level and ${ }^{* *}$ for $1 \%$ level or less. 
Several other variables besides the order dummy variable bear mentioning. The instrumental variable representing the difference in taste perception between rBST-free and conventional milk (TASTE_RC) is statistically significant, indicating the intuitive behavioral response that participants who thought that rBST-free milk of a given fat type tasted better than the conventional version of the same fat type were willing to pay more for it. Additionally, the more frequently a participant consumes either conventional or rBST-free milk (FREQ_CONV and FREQ_RBST), the larger the difference in WTP between rBST-free and conventional milk as both coefficients are positive and significant at the 0.05 level or better. Also, the coefficient on the variables related to whether the participant is the primary shopper (PRIME_SHOP) is large, a \$1.11 difference for a quart of milk, and statistically significant at the 0.01 level. This suggests that the household member who normally does the shopping is typically willing to pay more of a premium for rBST-free milk than those who do not. Importantly, these results imply that the stigma effect is not a phenomenon of naive and infrequent consumers but is something exhibited by experienced consumers of milk.

Participants who expressed concern about the riskiness of milk (MILK_RISK) were willing to pay a higher premium for rBST-free milk, as were those who had more education (EDUC) and those who bid higher than the induced value in the last practice round of the BDM mechanism.

\subsection{Difference in WTP Between Organic and Conventional Milk}

Column (2) in Table 5 shows the results of the model that uses the difference in WTP for organic and conventional milk as the dependent variable. This model again shows 
a stigma effect on WTP for conventional milk when it is presented after organic milk. In this case, the coefficient for the variable $O R$ is even larger (0.482) and statistically significant at the 0.01 level $(p=0.003)$. Thus, we can also reject the hypothesis that order does not affect WTP for organic and conventional milk. Subjects are willing to pay $\$ 0.48$ per quart less for conventional milk after tasting and being exposed to label information regarding organic milk (i.e., organic milk "produced without the use of antibiotics, synthetic growth hormones, or pesticides”). The larger stigma effect of organic compared with rBST-free milk on conventional milk is intuitive since organic milk is free of more than rBST, having additional claims of being pesticide and antibiotic free.

Additionally, the variable measuring the participants’ perceptions of the risks involved with consuming milk (MILK_RISK) was highly significant $(p=0.001)$ and had a positive coefficient (0.096). At the same time, several factors that are significant in the regression of WTP for rBST-free and conventional milk are not significant in this model. This could in part be driven by the higher level of preexisting information participants possessed regarding organic milk compared to rBST-free (92\% were aware of organic milk while 54\% were aware of rBST-free milk). Subjects who are willing to pay a high premium for organic milk likely are consumers who are already aware of its availability and reputation as a "safe" alternative to conventional milk. Hence, perception of the risks involved with consuming milk is a key factor in determining the price premium for organic milk. 


\subsection{Difference in WTP Between Organic and rBST-Free Milk}

Column (3) in Table 5 shows the results of the model for the difference in WTP for organic and rBST-free milk, with no significant difference in WTP based on the order of presentation (OR). Thus, we fail to reject the hypothesis that order does not affect WTP for organic and rBST-free milk. It is important to note that rejection of the null hypothesis does not indicate that participants were willing to pay the same amount for organic and rBST-free milk, only that the difference in WTP was not caused by the order of presentation.

The only variable that is statistically significant at the 0.05 level is the perception of milk risk (MILK_RISK), which had a positive coefficient (0.079). This indicates that participants view organic milk as a safer product than milk that is only rBST-free, likely due to the labels, which indicate that organic milk is produced without the use of antibiotics and pesticides. 


\section{Chapter 5}

\section{Conclusion}

The economic implications of the stigmatization of goods have not been thoroughly examined in the literature. Producers of conventional items have frequently been concerned about the negative consequences that may result from the introduction of new, similar products with labels touting better production methods, such as birdfriendly coffee, free-range chicken, sustainably harvested wood, and a variety of products marketed under the label of fair trade.

In the dairy industry, the use of recombinant bovine somatotropin (rBST), a synthetic version of a naturally occurring hormone, with milk-producing cows is an example of how stigma effects can have economic repercussions for the conventional product. The objective of this research was to determine whether the introduction of rBST-free and organic milk has a stigma effect on conventional milk. The question was addressed using experimental economics and by eliciting WTP measures from adult subjects for milk produced via different methods and varying in fat content. The advantage of using an experimental setting is the ability to observe directly the behavior of participants making actual purchase decisions as opposed to using survey techniques to pose hypothetical questions. The stigma effect was measured by altering the order in which participants were introduced to and asked to bid for the different types of milk.

The results of this study of 148 adult subjects indicate a substantial stigma effect from both organic and rBST-free milk on conventional milk. To measure the stigma effect, differences in WTP for milks with the same fat content were evaluated in three different models. Using a two-limit random-effect Tobit model to control for 
other factors affecting the difference in WTP, we find negative and statistically significant marginal effects for the coefficients on the variable measuring the stigma effect from organic on conventional milk and from rBST-free on conventional milk. Specifically, participants were willing to pay, on average, \$0.35 per quart less for conventional milk after tasting and being exposed to information regarding rBST-free milk (i.e., rBST-free milk “does not contain any artificial growth hormones”). This represents a 33\% reduction in WTP for conventional milk based on the overall average WTP in our study (\$1.06 per quart). There was an even stronger stigma effect from organic milk; participants were willing to pay, on average, $\$ 0.48$ per quarter less for conventional milk after tasting and being exposed to information regarding organic milk (i.e., organic milk "produced without the use of antibiotics, synthetic growth hormones, or pesticides”). This represents a 45\% reduction in WTP for conventional milk.

These results suggest that participants view conventional milk more negatively after the introduction of rBST-free and organic milk. This finding supports the idea that conventional milk becomes a stigmatized good after rBST-free and organic milk are introduced into the marketplace.

These results also indicate that all milk types (conventional, rBST-free, and organic) are stigmatized by the introduction of rBST-free and organic milk. The mean WTP for all three milk types when conventional milk was presented first was $\$ 1.22$; the mean WTP when conventional milk was presented third was $\$ 0.90$. This $\$ 0.32$ difference (26\%) was statistically significant at the 0.014 level. This finding suggests that the introduction of milk labeled as being rBST-free or organic could have a much greater influence than simply reducing WTP for conventional milk. That is, the introduction of rBST-free and organic milk could potentially reduce the demand for all types of milk. 
A caveat on these results should be noted. Our findings are based on observations from a laboratory experiment, which is not identical to real marketplace conditions. In particular, the introduction of organic and rBST-Free milk products in the real market occurred gradually over a substantially longer time period than was modeled in our experiment. Given the rapid, sequential introduction of all three product types in our experiment, our results likely represent a short-term measurement of the stigma effect. Further research into how long this stigma effect lasts is thus warranted.

The experimental results illustrate that the recent actions by Wal-Mart, Dean Foods, and Starbucks to ban conventional milk and supply only rBST-free (and organic) milk may have significant negative consequences for conventional milk demand. The implication of the stigma effect found here is that the dairy industry will have to confront this issue head-on or risk a possibly major negative impact on milk consumption. 
APPENDIX

APPENDIX 1: EXPERIMENT INSTRUCTIONS

\section{$\underline{\text { Instructions - (Part A) }}$}

Welcome to an experiment in the economics of decision making. In the course of the experiment, you will have opportunities to earn money. Any money earned during this experiment is yours to keep, thus please read these instructions carefully. Additionally, you are guaranteed a $\$ \mathbf{5 . 0 0}$ show-up fee for participating, regardless of what you may earn during the experiment. Please do not communicate with other participants during the experiment. As stated in the Consent Form, your participation in this experiment is voluntary.

In today's experiment, you will be asked to indicate the highest amount of money you would pay for different purchase decisions. We will refer to this amount as your bid. Sometimes a purchase decision will refer to a cash value and sometimes it will refer to a food item.

For the first several purchase decisions, the experiment proceeds as follows:

First, you will receive an initial balance of $\$ 5$. You will then be informed of your cash value that you would receive if you purchase the decision. Your cash values will vary during the course of the experiment. The possible amounts are $\$ 1, \$ 2.50$, and $\$ 4$.

You will then be asked to indicate the highest amount that you would pay for this purchase decision. For each decision, you can bid any amount between $\$ 0$ and your initial balance of $\$ 5$. Once you have decided your bid, you will type it into the computer spreadsheet, hit ENTER on the keyboard, and then click the "Submit" 
button. After everyone has submitted their bids, the price for the purchase decision will be determined.

The price will be determined by having a volunteer subject drop a pen onto a random number table. Since these numbers have been generated by a random number table each price between $\$ 0.00$ and $\$ 5.00$ is equally likely. Whether the decision is purchased depends on your bid and the randomly determined price. There are two possible outcomes:

\section{The decision is PURCHASED: The decision is purchased if your bid is equal to or} greater than the price. In this case, you will receive the cash value in addition to your initial balance of $\$ 5$. However, you will also have to pay the randomly determined price. Therefore, your earnings would be your initial balance, plus your cash value, minus the price.

\section{The decision is NOT PURCHASED: The decision is not purchased if your bid is}

less than the price. In this case, you will not receive the cash value, but you will not have to pay the price. Therefore, your earnings would simply be your initial balance of $\$ 5$.

In this setting, it is in your best interest (i.e. you will make the most possible earnings) if you submit bids equal to your cash value for the decision. Note that while your bid helps determine whether the decision is purchased, your earnings are calculated based on your initial balance, the cash value and the determined price (not your bid). For example, if a decision was not purchased and the cash value was \$2.50 and the determined price was $\$ 4.50$, your earnings would still be $\$ 5$. However, if the decision 
was purchased with the same cash value and price, your earnings would be \$3 (=\$5 + $\$ 2.50$ - \$4.50).

Example 1.

Outcome Initial Balance Cash Value Price Earnings

Purchased $\$ 5.00$ $\$ 2.50$ $-\$ 4.50$

$\$ 3.00$

Not Purchased

$\$ 5.00$

$\$ 2.50$

$-\$ 4.50$

$\$ 5.00$

Consider another example where the cash value was \$5 and the determined price was \$1. In this example if the decision was not purchased your earnings would again be $\$ 5$, while if the decision was purchased, your earnings would be $\$ 5.50$ (\$5 + \$2.50 \$1).

Example 2.

\begin{tabular}{lcccc} 
Outcome & Initial Balance & Cash Value & Price & Earnings \\
\hline Purchased & $\$ 5.00$ & $\$ 2.50$ & $-\$ 1.00$ & $\$ 6.50$ \\
Not Purchased & $\$ 5.00$ & $\$ 2.50$ & $-\$ 1.00$ & $\$ 5.00$
\end{tabular}

\section{Calculation of Earnings}

After everyone has submitted their bids for the decision and the price has been determined, the administrator will display all of the bids on the screen in the front of the room. These bids will be displayed anonymously from lowest to highest and no subject numbers will be associated with these bids. The administrator will then ask all the participants the following questions:

1) Can you identify your bid?

2) Which subjects purchased the decision? 
3) How much will these subjects have to pay and how much will they earn in this round?

4) How much will the subjects who did not purchase the decision earn in this round?

Then you will be asked to click the RECEIVE button and the computer will display whether you purchased the decision and calculate your earnings. The computer will add your experimental earnings for all of the rounds, and convert this amount to US dollars by applying an exchange rate of 2 experimental dollars to \$1 USD. For example, if you earn 20 experimental dollars, your monetary payoff from this part of the experiment would be $\$ 10$ USD. 


\section{Instructions - Part B}

\section{Pencil as the Purchase Decision}

You will be asked to indicate the highest amount of money you would pay for a pencil using the same procedures as discussed previously. In this case, your starting balance will be $\$ 0.50$ and you can submit any bid between $\$ 0$ and $\$ 0.50$. The random price will again be determined using a random numbers table, however, now the price will range from $\$ 0.00$ to $\$ 0.50$. In this part, there will not be an exchange rate as one experimental dollar will equal \$1 USD.

Note that in the case, you will need to determine the "highest amount" that you would pay to purchase this pencil. Again, it is in your best interest to submit a bid equal to this highest amount, since, if you purchase the pencil, you will pay the randomly determined price not your bid. The two possible outcomes are as follows:

\section{The pencil is PURCHASED: The pencil is purchased if your bid is equal to or} greater than the price. In this case, you will receive the pencil in addition to your initial balance of $\$ 0.50$. However, you will also have to pay the randomly determined price.

\section{The pencil is NOT PURCHASED: The pencil is not purchased if your bid is less}

than the price. In this case, you will not receive the pencil, but you will not have to pay the price. Therefore, your cash earnings would simply be $\$ 0.50$.

After everyone has submitted their bids and the price is determined, the administrators will distribute the pencils to the subjects which purchased them. 


\section{$\underline{\text { Instructions }-(\text { Part C) }}$}

The procedures are similar to the ones used in Part B of the experiment, with some important differences.

You will receive an initial balance of $\$ 5$. The purchase decision is one quart of milk. One quart of milk is equal to one-quarter gallon, or 32 fluid ounces. The milk is cold and fresh and is being stored in the refrigerator in the lab.

You will be making a total of nine purchase decisions regarding milk. However, only one of the nine milk types will be selected for implementation and will result in cash earnings. The type of milk that will be selected for implementation has been randomly determined prior to the experiment and this information has been placed in a dated, sealed envelope that will be opened at the end of the experiment. Each of the milk types is equally likely to be implemented. Therefore consider each decision as if it is the one that will be actually implemented.

You will be served a series of three flights of milk that you will be invited to taste. Each flight of milk consists of three different milk types. The milks will be placed a tasting sheet that provides information related to the milk you will be tasting.

After sampling each milk type, please complete the questions related to the milk you tasted and then submit a bid for each of the milks. Again, your bid should represent the highest amount that you would be willing to buy that one-quart of milk today. You may bid any amount between $\$ 0$ and $\$ 5$ for each milk type. The price for the decision will be determined in the same manner as in Part A using a new random number table. 
There are two possible outcomes:

The milk is PURCHASED: The carton of milk is purchased if your bid is equal to or greater than the price. In this case, you will receive the carton of milk in addition to your initial balance of $\$ 5$. However, you will also have to pay the randomly determined price.

The milk is NOT PURCHASED: The carton of milk is not purchased if your bid is less than the price. In this case, you will not receive the carton of milk, but you will not have to pay the price. Therefore, your cash earnings would simply be $\$ 5$.

Please do not submit your bid until instructed by the administrator.

In the event that the milk is purchased, you may either take it with you immediately, or store it in the lab until the end of the day. Milk that is stored in the lab may be picked up between 4 p.m. and 5 p.m.

It is important that you clearly understand these instructions. Please raise your hand if you have any questions. Please do not talk with other participants in the experiment 


\section{APPENDIX 2: TASTING}

TEMPLATE

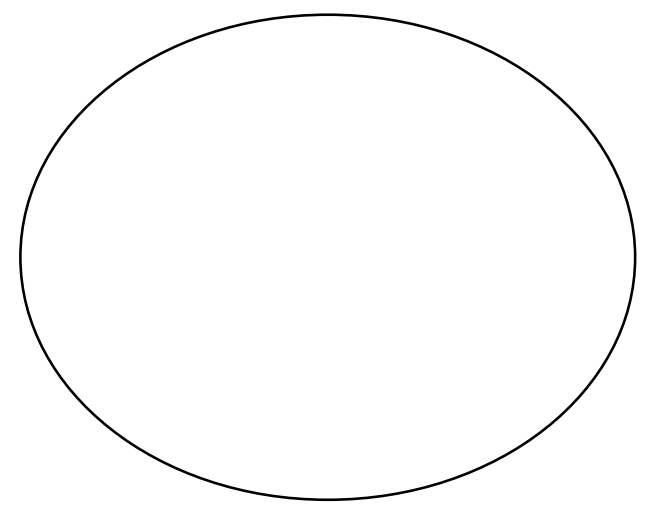

0\%MILK (Skim)

1) Please rate how closely this product matches your expectation of fresh, high quality milk $(1=$ Worse than Expected; 5 = Meets

Expectations; $10=$ Better than Expected).

\section{Worse than \\ Expected}

$$
\begin{array}{llllllllll}
1 & 2 & 3 & 4 & 5 & 6 & 7 & 8 & 9 & 10
\end{array}
$$

2) Please rate how much you like this product (from 1-10, with 10 being most favorable)
Least
Most
Favorable
Favorable

123

$\begin{array}{llllllll}3 & 4 & 5 & 6 & 7 & 8 & 9 & 10\end{array}$

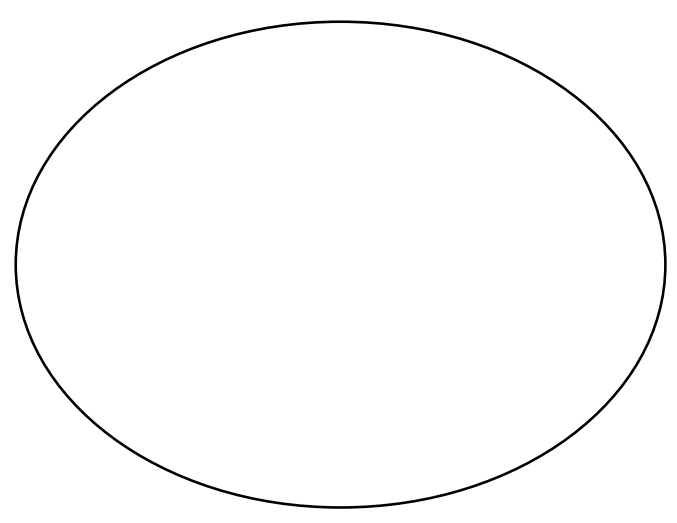

\section{1\%MILK (Low Fat)}

1) Please rate how closely this product matches your expectation of fresh, high quality milk

(1 = Worse than Expected; 5 = Meets

Expectations; 10 = Better than Expected).

\section{Worse than \\ Expected}

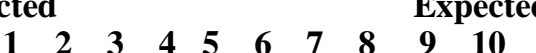

2) Please rate how much you like this product (from 1-10, with 10 being most favorable)

\section{Least}

Favorable

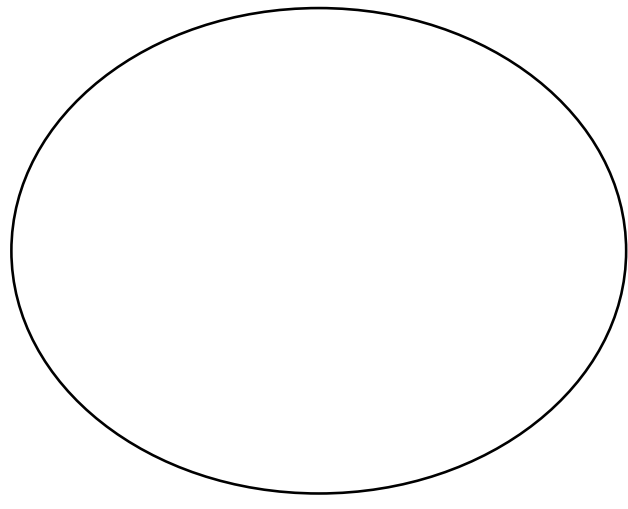

$3.25 \%$ MILK (Whole)

1) Please rate how closely this product matches your expectation of fresh, high quality milk

( 1 = Worse than Expected; 5 = Meets

Expectations; 10 = Better than Expected).

\section{Worse than}

Expected

Better than

$\begin{array}{lllllllll}1 & 2 & 3 & 4 & 5 & 6 & 7 & 8 & 9\end{array}$

2) Please rate how much you like this product (from 1-10, with 10 being most favorable)

Least

Most

Favorable

Favorable 


\author{
APPENDIX 3: NUTRITION \\ INFORMATION
}

\title{
Nutrition Information
}

\section{Nutrition Information: 0\% Fat (Skim)}

Serving Size:

Calories:

Calories from Fat:

1 cup (240 mL)

$$
90
$$$$
0
$$

$\omega$

\% Daily Value*

Total Fat:
Saturated Fat:

Trans Fat:

Cholesterol:

Sodium:

Carbohydrate:

Dietary Fiber:

Sugar:

Protein:

Vitamin A:

Calcium:

Vitamin D:

Vitamin C:

Iron:

*\% Daily Values are based on a 2000 calorie diet

Ingredients: Fat Free Milk, Vitamin A Palmitate, Vitamin D3 added.

\section{Nutrition Information: 1\% Fat (Lowfat)}

Serving Size:

Calories:

Calories from Fat:

1 cup $(240 \mathrm{~mL})$

$100-110$

20

\% Daily Value*

Total Fat:

Saturated Fat:

Trans Fat:

Cholesterol:

Sodium:

Carbohydrate:

Dietary Fiber:

Sugar:

Protein:

Vitamin A:

Calcium:

Vitamin D:

Vitamin C:

Iron:

$\begin{array}{ll}2-2.5 \mathrm{~g} & 3-4 \% \\ 1-1.5 \mathrm{~g} & 5-8 \% \\ 0 \mathrm{~g} & \\ 10-15 \mathrm{mg} & 3-4 \% \\ 125-130 \mathrm{mg} & 5 \% \\ 11-13 \mathrm{~g} & 4 \% \\ 0 \mathrm{~g} & 0 \% \\ 11-12 \mathrm{~g} & \\ 8 \mathrm{~g} & 16 \% \\ & 10 \% \\ & 30 \% \\ & 25 \% \\ & 2-4 \% \\ & 0 \%\end{array}$

*\% Daily Values are based on a 2000 calorie diet

Ingredients: 1\% Lowfat Milk, Vitamin A Palmitate, Vitamin D3 added.

\section{Nutrition Information: 3.25\% Fat (Whole)}

\begin{tabular}{lll} 
Serving Size: & $1 \mathrm{cup}(240 \mathrm{~mL})$ \\
Calories: & 150 & \\
Calories from Fat: & 70 & \\
& & \\
\% Daily Value* & & \\
Total Fat: & $8 \mathrm{~g}$ & $12 \%$ \\
Saturated Fat: & $5 \mathrm{~g}$ & $25 \%$ \\
Trans Fat: & $0 \mathrm{~g}$ & \\
Cholesterol: & $30-35 \mathrm{mg}$ & $10-11 \%$ \\
Sodium: & $120-125 \mathrm{mg}$ & $5 \%$ \\
Carbohydrate: & $11-12 \mathrm{~g}$ & $4 \%$ \\
Dietary Fiber: & $0 \mathrm{~g}$ & $0 \%$ \\
Sugar: & $11-12 \mathrm{~g}$ & \\
Protein: & $8 \mathrm{~g}$ & $16 \%$ \\
Vitamin A: & \multicolumn{2}{c}{$4 \%$} \\
Calcium: & & $30 \%$ \\
Vitamin D: & & $25 \%$ \\
Vitamin C: & & $4 \%$ \\
Iron: & & $0 \%$
\end{tabular}

*\% Daily Values are based on a 2000 calorie diet Ingredients: Milk, Vitamin D3 added. 
APPENDIX 4: POST-EXPERIMENT QUESTIONNAIRE

\section{Post-Experiment Questionnaire}

Note: Please make sure to complete the questionnaire before leaving the lab.

1. How thirsty were you during the experiment?

$$
\text { Not Thirsty 1----2----3----4----5----6----7----8----9 Very Thirsty }
$$

2. In the typical week, approximately how much milk does your household consume?

$$
\text { gallons } \quad(1 \text { quart }=1 / 4 \text { gallon })
$$

3. How often does your household drink:

$\begin{array}{llllll}\text { Conventional Milk: } & \text { Never } & \text { Rarely } & \text { Sometimes } & \text { Often } & \text { Always } \\ \text { RBST-Free Milk: } & \text { Never } & \text { Rarely } & \text { Sometimes } & \text { Often } & \text { Always } \\ \text { Organic Milk: } & \text { Never } & \text { Rarely } & \text { Sometimes } & \text { Often } & \text { Always }\end{array}$

4. $\quad$ Are you the primary shopper in your household? $\square$ Yes $\quad \square$ No

5. Including yourself, how many people live in your household? people

6. Including yourself, does anyone in your household have any milk allergies or lactose intolerance?
$\square$ Yes
$\square$ No 
7. Before today, were you aware of the availability of rBST-Free milk?

$\square$ Yes $\quad \square$ No

8. Before today, were you aware of the availability of organic milk?

$\square$ Yes $\quad \square$ No

9. How concerned are you about the following in your milk?

Pesticides:

Not Concerned

Very Concerned

Antibiotics:

1----2----3-----4----5-----6----7----8----9

Artificial Hormones:

1----2----3----4----5----6----7----8----9

Herbicides/Fungicides:

1----2----3----4----5-----6----7----8----9

1----2----3-----4----5-----6----7----8----9

10. What is your country of origin? $\square$ U.S. $\square$ Other

11. What is your gender? $\square$ Female $\square$ Male

12. Do you have children? $\square$ Yes $\square$ No

If yes, how many children live at home?

What are their ages?

13. What is your highest level of education obtained?
Some High School
High School Degree
Some College
$\square$ College Degree
$\square$ Graduate Work
Other (please
list)

14. What is your annual household income?

$\begin{array}{lll}\square \text { \$0-\$10,000 } & \square \text { \$10,001-\$20,000 } & \square \$ 20,001-\$ 30,000 \\ \square \text { \$30,001-\$40,000 } & \square \$ 40,001-\$ 50,000 & \square \$ 50,001-\$ 60,000\end{array}$




$\square$ \$60,001-\$70,000 $\square$ \$70,001-\$80,000 $\square$ \$80,001-\$90,000
$\square$ \$90,001-100,000 $\square$ \$100,001-\$110,000 $\square$ \$110,001-\$120,000
$\square$ \$120,001-\$130,000 $\square$ \$130,001-\$140,000 $\square$ \$140,001-\$150,000
$\square$ more than $\$ 150,000$

15. How risky do you consider drinking conventional milk?

Not Risky 1----2-----3----4-----5----6----7----8----9 Very Risky 


\section{REFERENCES}

Adams, G., and R. Cantor. 2001. "Risk, Stigma, and Property Value-What Are People Afraid Of?” Risk, Media and Stigma: Understanding Public Challenges to Modern Science and Technology. J. Flynn, P. Slovic, and H. Kunreuther, eds. Sterling VA: Earthscan Publications Ltd, pp. 175-186.

Barham, B., J.D. Foltz, S. Moon, and D. Jackson-Smith. 2004. “A Comparative Analysis of Recombinant Bovine Somatotropin across Major U.S. Dairy Regions.” Review of Agricultural Economics 26:32-44.

Becker, G.M., M.H. DeGroot, and J. Marschak. 1964. “Measuring Utility by a SingleResponse Sequential Method.” Behavior Science 9:226-232.

Bernard, J.C., and D.J. Bernard. In press. "What Is It about Organic Milk? An Experimental Analysis.” American Journal of Agricultural Economics.

Bernard, D.J., and A. Mathios. 2005. "Factors Affecting Consumer Choice and Willingness to Pay for Milk Attributes.” Selected paper at the American Agricultural Economics Association annual meeting, Providence RI.

Chapman, K.W., and K.J. Boor. 2001. “Acceptance of 2\% Ultra-pasteurized Milk by Consumers 6 to 11 Years Old.” Journal of Dairy Science 84:951-954.

Chapman, K.W., H.T. Lawless, and K.J. Boor. 2001. “Quantitative Descriptive Analysis and Principal Component Analysis for Sensory Characterization of Ultra Pasteurized Milk.” Journal of Dairy Science 84:12-20.

Corrigan, J.R., and M.C. Rousu. 2006. “The Effect of Initial Endowments in Experimental Auctions.” American Journal of Agricultural Economics 88:448-457. 
Dale, L., J.C. Murdoch, M.A. Thayer, and P.A. Waddell. 1999. “Do Property Values Rebound from Environmental Stigmas? Evidence from Dallas.” Land Economics 75:311-326.

Dhar, T., and J.D. Foltz. 2005. "Milk by Any Other Name . . Consumer Benefits from Labeled Milk.” American Journal of Agricultural Economics 87:214228.

Fallert, R., T. McGuckin, C. Betts, and G. Bruner. 1987. bST and the Dairy Industry: A National, Regional, and Farm Level Analysis. Washington DC: U.S. Department of Agriculture, Economic Research Service.

Forbes, B. 2008. “Loss of Milk Production Booster Could Cost Dairy Farmers, Consumers.” Purdue News Service, Purdue University, 31 January. Available at http://news.uns.purdue.edu/x/2008a/080131SchutzMilk.html.

Fox, J.A., D.J. Hayes, and J.F. Shogren. “Consumer Preferences for Food Irradiation: How Favorable and Unfavorable Descriptions Affect Preferences for Irradiated Pork in Experimental Auctions.” The Journal of Risk and Uncertainty 24(2002):75-95.

Guntermann, K.L. 1995. "Sanitary Landfills, Stigma and Industrial Land Values.” Journal of Real Estate Research 10:531-542.

Hayes, D.J., J.F. Shogren, S.Y. Shin, and J.B. Kliebenstein. "Valuing Food Safety in Experimental Auction Markets.” American Journal of Agricultural Economics 77(1995):40-53.

Horowitz, J.K. 2006. “The Becker-DeGroot-Marschak Mechanism Is Not Necessarily Incentive Compatible, Even for Non-Random Goods.” Economics Letters 93:6-11. 
Irwin, J.R., G.H. McClelland, M. McKee, W.D. Schulze, and N.E. Norden. 1998. “Payoff Dominance vs. Cognitive Transparency in Decision Making.” Economic Inquiry 36:272-285.

Kaiser, H.M., C.W. Scherer, and D.M. Barbano. 1992. “Consumer Perceptions and Attitudes toward Bovine Somatotropin.” Northeastern Journal of Agricultural and Resource Economics 21:10-20.

Karni, E., and Z. Safra. 1987. “ ' Preference Reversal’ and the Observability of Preferences by Experimental Methods.” Econometrica 55:675-685.

Louviere, J. 2006. “What You Don’t Know Might Hurt You: Some Unresolved Issues in the Design and Analysis of Discrete Choice Experiments.” Environmental \& Resource Economics 34:173-188.

Lusk, J., T. Feldkamp, and T. Schroeder. 2004. "Experimental Auction Procedure: Impact on Valuation of Quality Differentiated Goods.” American Journal of Agricultural Economics 86:389-405.

Martin, A. 2007. “Consumers Won’t Know What They’re Missing.” New York Times, 11 November. Available at www.nytimes.com/2007/11/11/business/11feed.html.

McGuckin, J.T., and S. Ghosh. 1989. “Biotechnology, Anticipated Productivity Increases, and U.S. Dairy Policy.” North Central Journal of Agricultural Economics 11:277-288.

McGuirk, A.M., and H.M. Kaiser. 1991. “bST and Milk: Benefit or Bane?” Choices, first quarter:20-26.

Messer, K.D., W.D. Schulze, K.F. Hackett, T. Cameron, and G. McClelland. 2006. “Can Stigma Explain Large Property Value Losses? The Psychology and Economics of Superfund.” Environmental and Resource Economics 33:299_ 324. 
Messer, K.D., H.M. Kaiser, C. Payne, and B. Wansink. In Press. “Measuring the Impact of Media Information about Mad Cow Disease on Consumers’ Willingness-to-Pay and Risk Attitudes” Applied Economics.

Noussair, C., S. Robin, and B. Ruffieux. 2004. “Do Consumers Really Refuse to Buy Genetically Modified Food?” The Economic Journal 114:102-120.

Rozin, P. 2004. “Technological Stigma: Some Perspectives from the Study of Contagion.” Risk, Media, and Stigma: Understanding Public Challenges to Modern Science and Technology. J. Flynn, P. Slovic, and H. Kunreuther, eds. Sterling VA: Earthscan Publications Ltd, pp. 31-40.

Rozin, P., L. Millman, and C. Nemeroff. 1986. “Operation of the Laws of Sympathetic Magic in Disgust and Other Domains.” Journal of Personality and Social Psychology 50:703-712.

Shogren, J.F., S. Shin, D.J. Hayes, and J.B. Kliebenstein. 1994. “Resolving Differences in Willingness to Pay and Willingness to Accept.” American Economic Review 84:255-270.

Tauer, L., and H.M. Kaiser. 1991. “Optimal Dairy Policy with Bovine Somatotropin.” Review of Agricultural Economics 13:1-17.

Viscusi, W.K. “Alarmist Decisions with Divergent Risk Information.” The Economic Journal 107(1997):1657-1670. 